\title{
Knowledge Management Systems Development: Theory and Practice
}

\author{
Raafat Saade, Fassil Nebebe, and Tak Mak \\ Concordia University, Montreal, Canada
}

\author{
rsaade@jmsb.concordia.ca; fnebebe@jmsb.concordia.ca; \\ tmak@jmsb.concordia.ca
}

\begin{abstract}
The intricate crafting of online educational systems lie within three principal activities: Design of the system, implementation, and proper post-implementation assessment. There is not enough knowledge or experience in all regards. Efficient execution of these three major activities necessitates the use of design and pedagogical models to achieve cost and time efficiency, as well as high pedagogical quality. Models represent a structured approach to analysis and promote quantifiable feedback that can be monitored. Components of an online educational system would benefit from a design process. Similarly, utilization of the online educational system would benefit from a structured approach to design, implementation, and student's assessment. Following the technology adoption theory, understanding individual's behavior towards technology usage would focus on instrumental beliefs driving intentions. However, this may not be the case with online educational systems because the context and setup is significantly different from previous technology adoption studies. Therefore, the implementation of an online educational system should be designed based on established pedagogical principles, and once developed the assessment of students' behavior should be monitored using management information systems methodology.

In this paper, we present the design of an online education system, and the experience of the students using the system. A survey methodology approach is followed and assessment results are discussed. The technology acceptance model and the theory of planned behavior were used to identify significant constructs as antecedents to intentions. Scale validation for both models indicates that the operational measures have acceptable psychometric properties. Confirmatory factor analysis supports both models. Structural equation analysis provides evidence for the superiority of the theory of planned behavior in explaining students' behavior towards educational online systems. Limitation, implications, design recommendations, and suggestions for future research are then discussed.
\end{abstract}

Keywords: Theory of planned behavior, Technology acceptance model, Web-based instructional systems, elearning, PLS, Constructiv-

Material published as part of this publication, either on-line or in print, is copyrighted by the Informing Science Institute. Permission to make digital or paper copy of part or all of these works for personal or classroom use is granted without fee provided that the copies are not made or distributed for profit or commercial advantage AND that copies 1) bear this notice in full and 2) give the full citation on the first page. It is permissible to abstract these works so long as credit is given. To copy in all other cases or to republish or to post on a server or to redistribute to lists requires specific permission and payment of a fee. Contact Publisher@InformingScience.org to request redistribution permission. ism, Cognitive

\section{Introduction}

In today's global, digital, and networked economy, information technology represents a substantial investment for most corporations and constitutes a significant aspect of organizational work (Agarwal \& Karahanna, 2000). In the education sector, a major trend in online 
courses is immerging such that the value of the information technology investment is realized only when the instructional information systems developed are utilized by the students in a manner that contributes to their learning process. Online instruction is a relatively new phenomenon for most faculty members, such that few consider themselves as experts in the field (Sunal, Sunal, Odell, \& Sundberg, 2003). Most of the research today reports on differences between face-to-face and online teaching and on new student experiences in online learning. Other concerns being explored are student achievement and attitudes, course design and delivery, course evaluation, and instructor behaviors and attitudes. Evaluation of these factors utilizing well-developed research methodologies are few (Saadé \& Kira, 2009, Sunal et al., 2003,), and there is a great need to not only investigate these factors but also evaluate them based on strong theoretical basis. In this study, we view the course content as knowledge that the instructor holds tacitly or knows the sources to obtain them and the online educational system (OES) as the information system that contains this knowledge that it would have to manage including the processes of delivering it to the students. In this paper, we review the literature on knowledge management to elaborate on two of its most important aspects, namely, the human and the social aspects. These two aspects are critical in learning because they represent two primary streams of processing, namely, cognitive and social. Learning takes place along both of these aspects. These have implications to the design of the OES. Considering the theoretical models used to assess satisfaction of e-learning, one would find that these models in most cases represent the cognitive domain (such as the technology acceptance model), the social domain (such as the theory of planned behavior), or both. To that effect, we formulate the assessment theoretical framework of the proposed online educational system based on the cognitive (human/individual) and social domains and test their power to explain the proposed design of the OES.

\section{General Perspective of Knowledge Management}

Knowledge has always been considered as power. The meaning of the word knowledge has been discussed for thousands of years (Avdic \& Westin, 2002). It has been traditionally associated with individuals in organizations who possess this knowledge (Davenport \& Prusak, 1998). "Knowledge has become the key economic resource..." (Drucker, 1995). Knowledge work performed by professionals and managers will account for nearly $25 \%$ of the workforce soon after the $21^{\text {st }}$ century, and, as a result, $40 \%$ of Fortune- 1000 companies claim to have established the role of Chief Knowledge Officer (CKO) in their companies (Nissen, Kamel, \& Sengupta., 2000; Roberts, 1996). Recently, interest in, and attention to, knowledge management systems has significantly increased in academic institutions, which depend upon knowledge-work processes to compete (McCartney, 1998).

Managing knowledge has been found to be a difficult task (Davenport, 1995) and continues to be so to this day. For one thing, the management of knowledge is heavily information technology (IT) dependent, and the creation and utilization of knowledge is dependent on the individual (instructor and student) and his/her activities. Moreover, a substantial amount of knowledge is tacit, unstructured, and external (Nissen et al., 2000). Other variables contributing to the difficulty of knowledge management include the storage of historical knowledge on paper and the storage of experiential knowledge in the minds of instructors. Knowledge stored on paper and in the minds of instructors is vulnerable to loss via natural disasters and theft and via employee turnover, attrition and downsizing (McCartney, 1998).

Today, and in the instructional context, computers are used to process knowledge (course content) for storing and transferring, hence managing. This computerized process of managing knowledge is presented to humans for interpretation. With interpretation, humans learn and gain knowledge, hence create knowledge. Therefore, the knowledge management where students interact with computers to learn and gain knowledge can be viewed as an active process of learning. 
Students act on knowledge present in their minds to attain an objective or accomplish a goal and, by doing so, increase their knowledge one more time. Knowledge does not belong to a separate cognitive sphere. It is related to practice in various ways (Nurminen, 1995).

\section{Human and Social Aspects of Knowledge Management}

Knowledge management can be viewed as getting the right information to the right people at the right time. This reveals two important indications: (1) Time, which is an indication of cognition, and (2) People, which implies the existence of a social dimension to the management of knowledge that paid little attention to human and social factors (Thomas, Kellogg, \& Erickson, 2001). The authors of this paper agree with Thomas in that all the elements of knowledge and knowledge management influence and, in turn, are influenced by human cognition while knowledge is being created, extracted, manipulated, disseminated, and used, not alone but within the social milieu it is taking place.

When we are dealing with the human aspect of knowledge management, two primary variables come into play: (1) intelligence and (2) learning. There are different types of intelligence that work on different forms of knowledge. Three levels of human intelligence, mainly products, operations, and content, were identified (Guilford, 1963); products included units, classes, and systems; operations or processes included cognition, memory, divergent thinking, convergent thinking, and evaluation; content entailed figural, symbolic, semantic, and behavioral. A lot of research suggests that it is very important to engage actively in the process of knowledge acquisition in order to learn it. Theoretical work done by the Vygotski (1962) and Piaget and Inhelder (1969) have shown that simply by presenting information to individuals does not mean that this results in learning. Individuals have to become actively involved in order for a change of behavior to occur. Vygotsky stressed that the insight to this learning process is a significant social component even if the knowledge was mathematical or scientific.

In addition, the behavior of individuals is highly influenced by the context. In one study, it was shown that people are much more likely to help a person in distress if they are alone rather than if they are with a large group. However when asked whether they would behave differently if more people were around, they claimed this would make no difference. This is a clear indication that people are very much influenced by the social context they live in. Knowledge work is not a solitary occupation. It is not even sufficient to say that knowledge work involves a group of people. Previous research has made it clear that knowledge work involves communication among loosely structured networks and communities of people and that understanding it involves identifying the social practices and relationships that are operative in a particular context (Thomas et al., 2001). Previous research has shown a variety of social factors influencing the social context of knowledge management and how these interact with technologies intended to support collaboration (Olson \& Olson, 2000).

\section{Knowledge Utilization in Education}

Over the past half-century, information scientists' concerns have changed significantly, such that research has diversified from the physical sciences to social and behavioral sciences along with a wide range of applied fields (Hood, 2002). Scientific and technical information is rarely sufficient to meet users' needs. This is due to the complex nature of human needs which vary across organizational structure and in time. Technical information alone is not sufficient. What we do with that information and how we interact and adapt to it and with it in time is the primary concern. All these changes in our understanding have had a profound effect on our conceptions of the design and implementation of effective information systems, hence our conceptions of knowledge and associated knowledge utilization. 
Knowledge management is seen by many as structured ways of making knowledge explicit and sharable in a specific context in a specific community, accomplished in several ways with or without information technology (Avdic \& Westin, 2002). It has been argued that using information technology for knowledge management does not guarantee improved performance (Nissen et al., 2000).

Most researchers agree that knowledge management is difficult. This is due to the fact of the inherent nature of knowledge, which is highly dependent on the two primary variables: the human element and the social context. Considering knowledge and knowledge management in the context of education, we quote Drucker (1994):

"Education will become the center of the knowledge society, and the school its key institution. What knowledge must everybody have? What is 'quality' in learning and teaching? These will, of necessity, become central concerns of the knowledge society, and central political issues. In fact, the acquisition and distribution of formal knowledge may come to occupy the place in the politics of the knowledge society which the acquisition and distribution of property and income have occupied in our politics over the two or three centuries that we have come to call the Age of Capitalism."

Online Educational Systems could serve the learning process whose primary objectives are to acquire and assimilate knowledge and to improve performance. The importance of an OES is that it serves as a tool to disseminate data and communicate information. Meaning and knowledge is created in a learning process supported by the OES. It was noted that in the knowledge environment, cognition, constructivism, and the social nature are major drivers for the creation of new knowledge (Hood, 2002). Experiential learning theory suggests a holistic perspective on learning that combines experience, perception, cognition, and behavior (Kolb, 1984).

\section{Knowledge Management as Viewed in This Paper}

Knowledge management in this paper is viewed primarily as a process allowing the acquisition, dissemination, organization, and assimilation of information. This process is facilitated with the help of an Online Educational System. This system is designed to meet the challenges raised by knowledge management researchers, namely, the human and social factors. To that effect, knowledge is bound up with human cognition, and it is created, used, and disseminated in ways that are inextricably entwined with the social milieu. In this study, we adopt this viewpoint, that knowledge management systems (in this case, it is the OES) should consider both human and social factors in the design. We believe that these factors are vital parts of any electronic form of educational systems (sometime called instructional systems). At the same time, we acknowledge other factors that play significant roles in knowledge management within the educational context.

This paper is then motivated by the need to present the design of an OES and student assessment results that were carried out using a survey methodology approach.

The issues related to knowledge management within the educational context are quite diverse because they are drawn from a variety of areas ranging from the cognitive sciences to learning theories and computer supported work. The diverse issues discussed in this paper reveal the complexity and subtlety of managing knowledge.

The OES was designed based on cognition (representing the human aspect of knowledge management for e-learning), constructivism (representing the social aspect of knowledge management for e-learning), and Web-based instructional systems theories. Assessment of intentions towards the acceptance and use of the OES was done via a survey methodology approach based on the technology acceptance model (TAM) and the theory of planned behavior (TPB). A brief review of relevant prior research in each of the design and assessment components follows. 


\section{Theoretical Development}

Different theories of learning and instruction exist. From one perspective, cognitive processing focused on processing and representing knowledge (Dole \& Sinatra, 1998; Jonassen, Davidson, Collins, Campbell, \& Haag, 1995; Miller \& Miller, 1999). From another, cognitive constructivism is a learning approach focused on how knowledge is constructed (Cronin, 1997; Jonassen et al., 1995). Prior to the 1990s cognitive processing was based on the idea that knowledge is external to the learner. During the 1990s, cognitive processing refocused attention to the idea that knowledge occurs internally as part of mental processes. Knowledge from an objectivist epistemology is seen as an entity which contains an objective and which exists separately (Miller \& Miller, 1999). This knowledge has identifiable attributes, relationships, and structure (Cronin, 1997). In the context of education or learning, one must consider the instructor/OES (or knowledge expert) and the learner (the knowledge worker). As a knowledge expert, the instructor/OES embodies an accurate representation of the knowledge attributes, relationships, and structure. As a learner, he/she is involved in the acquisition, internalization, and utilization of this external knowledge (Cronin, 1997; Jonassen et al., 1995).

Recently, the constructivist approach to learning has become widely accepted in the educational community (Dalgarno, 2001; Saadé \& Huang, 2009). Modern constructivism entails the idea that the construction of knowledge occurs within the mind as per the individual's internal mental processes and his/her perception of the world he/she lives in. Piaget (1952), one of the most influential contributors to modern thinking of constructivism, contented that the process of thinking and learning involves the linking of new knowledge acquired from the external environment and old knowledge, which has been already internalized. This linking between new and past knowledge occurs through the active process of organizing, ordering, classifying, relating, transforming, and explaining. This is where the individual is 'acting on' to create knowledge rather than 'taking in' to store external knowledge as acquired (Ewing, Dowling, \& Coutts, 1998).

A wide range of computer assisted learning resources integrate constructivist elements. The various types of computer assisted learning resources that tend to be labeled constructivist are described as:

- Hypermedia environments consisting of static text, graphics and other media (Low interactivity),

- Resources that include computer mediated communications tools entailing interaction between members of the learning community (Low interactivity) and

- Resources (High interactivity) that

- Allow learner to explore conceptual ideas

- Allow learner to manipulate information

- Allow learner to construct their own representation of knowledge

- Provide feedback to learner

Such resources include simulations, microworlds, intelligent agents, adaptive systems, cognitive tools, and practice tools.

Instructional systems in a higher education context aim at supporting and automating, to a certain degree, the instructional process of a specific course (Retalis \& Avgeriou, 2002, Saadé, Nebebe, $\&$ Tan, 2007). The objective of these systems is to satisfy the instructional needs for a specific subject domain caused by the advances in research and technology, the emergence of the information society and globalization (Hodgson, 1997). One of the major trends in education in North America has to do with how students will learn in the emerging technology. This is highlighted by a survey whose results show that in 1998 almost a quarter of all college courses currently em- 
ploy web pages for class material and resources, up from $8 \%$ just two years prior to that (Green, 1998; Ruzic, 2000). Assuming the same rate of $17 \%$ every two years, then this implies that today the web page (or internet presence) expectations would be well above $50 \%$.

Nowadays, instructional systems make extensive use of the internet technologies because they have the potential to advance interactivity between the learner and the content, the learner and the instructor, and the learner and another learner, offer flexibility in learning, and provide reusable resources (McCormack \& Jones, 1997; Saadé et al., 2007). This trend of using internet technologies to build instructional systems involves a high level of system complexity, a high level of technology use and integration, a strong instructional/pedagogical component, and organizational and administrative components (Carlson, 1998; Moore \& Kearsley, 1996).

Interactive multimedia learning material offers many pedagogical advantages, which address instructors and learners' needs (Hunt, 1998; Saadé \& Kira, 2007). Bill Atkinson, the creator of HyperCard (the first widely available hypermedia tool) in one of his speeches to the public, referred to hypermedia as an electronic construction net, which creates new possibilities for teaching and learning. There are several significant elements supporting the use of web-based instructional systems for learning:

- Text, graphics, videos and sound create a multi-sensory experience, which is more likely to be remembered.

- The interactivity process promotes higher order thinking skills via the decision-making that learners have to make for the selection of required learning tasks and continuous evaluation of the learning objectives and outcomes (Azarmsa, 1991; Saadé \& Huang, 2009).

- Teacher-student and student-student relationships are enhanced. The creation of multi-media and hypermedia materials fosters cooperative relationships among learners as they work together to share the creativity and responsibility needed to produce such a project.

A web-based instructional system for learning is not simply created by including interactivity and multimedia. There is a strong urge to include the "learning" component into the design. Mayer's (1989) learning process model provides a theoretical framework for incorporating "learning" knowledge into the web-based instructional system. Figure 1 shows Mayer's learning process model adapted to the theoretical background of e-learning today and aligned with knowledge management concepts (as per the discussion above).

Mayer's (1989) original learning process model (LPM) entailed the summation of materials to be learned, presentation method, and learner characteristics affecting the learning process followed by learning outcome then learning performance. A feedback loop is identified from the learning outcome to the learner characteristics. From a knowledge management perspective, we modified Mayer's LPM into a Knowledge Learning Model (KLM) as follows:

- Material to be learned is replaced by resources because material includes only content which may be viewed as static and tangible while the term resources implies a wider range of material including the tangible, intangible, and technology mediated.

- Presentation method is suggesting the way by which the material is to be delivered. Instead, implementation was used to imply the combination of technology, content, and context as part of the delivery of content mechanism.

- Learner characteristics is student-centered, however, learning is a holistic experience and all stakeholders take part. Therefore, stakeholders is used in the KLM to include teachers, students, teaching assistants, technical support, and others who play various roles during the learning system. 
- Resources, implementation, and stakeholders are engaged in different relationships which define the methods of the KLM.

- These methods are then facilitated by technology to streamline the delivery of the learning process. The learning process delivery system/component includes elements such as the human-computer interface, quality assurance, security and authentication, and monitoring and controls.

- Finally, outcome and performance is joined into one construct - learning outcome, which includes performance and satisfaction. The feedback loop in the KLM is from the learning outcome to all three (resources, implementation, and stakeholders) components of the model.

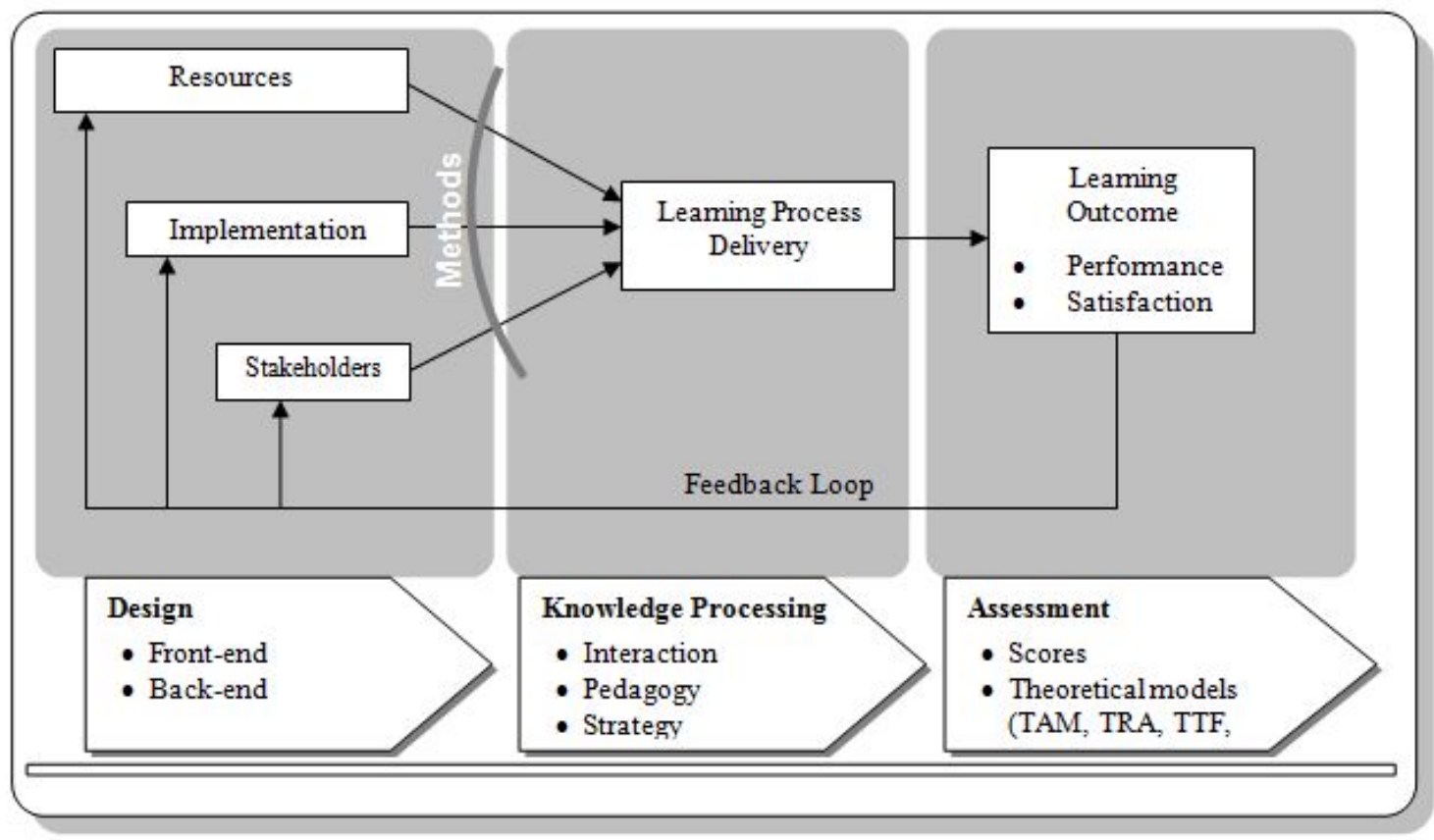

Figure 1: Theoretical Model for Learning Process.

The KLM is mapped into three implementation components elaborated in detail in the next section. These three components entail the design of the back-end and front-end of the OES, knowledge processing (which entails interaction between the different stakeholders, learning strategy, and pedagogy - referred to in the next section as the learning architecture), and assessment, namely, performance and satisfaction.

The design of the OES has been implemented in-house over a period of six years. The assessment of our OES is discussed with respect to student satisfaction in using the OES. A separate section was dedicated to the assessment because it entails a rigorous development including theory, methodology, and results.

\section{Design of Online Educational System}

\section{Learning Architecture}

The primary objective of the OES is the accurate transmission and reception of knowledge. This objective is the driving force behind the knowledge construction and communication tenet including strategies that determine communication between learner and content, instructor and learner, and among learners. 
The key to implementing these strategies lies in the analogy between mental structures and processes and the associative structure and hyper-linking processes of the web. The challenge is to construct an instructional environment so that it accurately reflects the expert's (in this case the instructor) knowledge structure (Miller \& Miller, 1999). There is however a pit fall to the limitless hyper-linking possibilities of the web in that it can compromise the learning process and detour the learner from the prescribed learning activities. Organization, degree of navigation, and level of interactivity are the primary critical decisions that the instructor needs to make during the development of the online course, if a faithful communication of the expert's knowledge is to be achieved (Miller \& Miller, 1999).

Retalis and Avgeriou (2002) explain that the underlying idea of modeling web-based instructional systems (in the present paper referred to as online educational system) is an explicit division of the instructional system into specific subsystems. These subsystems should meet instructional and pedagogical principles elucidating communication between learner and content, instructor and learner, and among learners. Retalis and Avgeriou proposed a web-based instructional system and described non-technical and technical components. Oliver, Herrington, and Omari (1996) identify the constitutive elements of effective online learning environments. The present OES builds on the subsystems identified by Retalis and Avgeriou and the constitutive elements presented by Oliver et al. (1996) by integrating pedagogical (learning) principles in the design. More specifically, the cognitive constructivism paradigm is represented by the subsystems.

Following the terminology presented by Retalis and Avgeriou (2002), three constitutive subsystems for effective learning are identified. An architectural blue print is presented in Figure 2: The human subsystem, the resources subsystem, and the implementation subsystem.

The human subsystem includes the learner and the instructor and responds to their individual and respective needs. The roles of each human agent involved in the instructional process are described (Lindner, 2001). The resources subsystem includes online (such as course notes, presentations and other documentation) and non-online material (such as textbooks and CD ROMs). The implementation subsystem entails the use of pedagogical and instructional strategies supporting learning. 


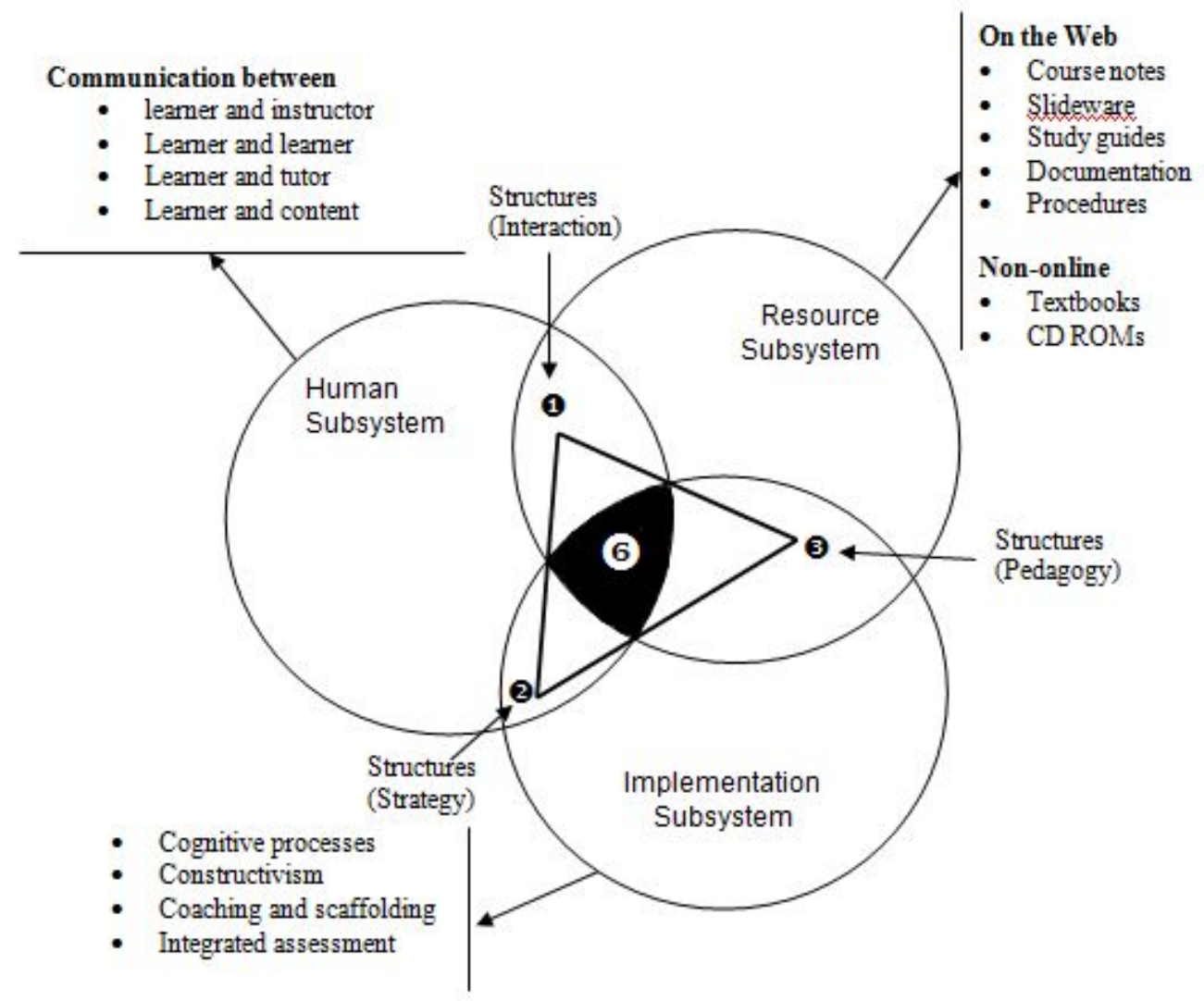

(1) Human to resources link via interaction structures is made possible by various leaming tools/objects developed using different software technologies. At this intersection, different stakeholders interact with the various resources to complete specific tasks.

2 Human to implementation link via strategy maps the process engagement of different stakeholders with the learning/educational system. At this intersection, the designer creates opportunities to students to build learning strategies they feel is appropriate for them.

3 Implementation to resources link via pedagogical structures represents the approach to learning as viewed by the designer. At this intersection, the designer builds his/her view of the learning process and the students experiences it.

- The learning domain is found at the intersection of the three subsystems and is facilitated by the different structures (the structures triangle). At this intersection, the OES draws on cognition and affective components and interactions to define the learning experience.

Figure 2: Knowledge Architecture in the Online Educational Subsystems.

\section{The Human Subsystem}

The human agents and their roles are given in Table 1. The OES does not entail any physical classes. However, there are tutorials given by a tutor to help students enhance their productivity skills. This includes learning how to use different desktop software such as MS Access and learning basic html. 
Table 1: Human Agents' Roles

\begin{tabular}{|c|c|}
\hline Human Agent & le \\
\hline Learner & 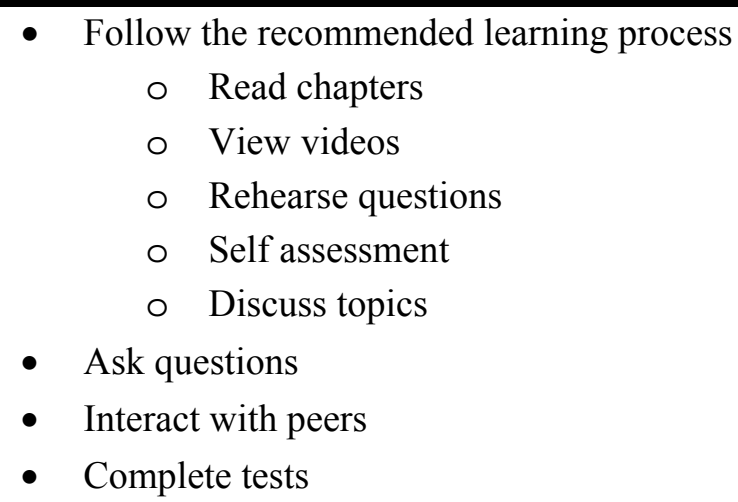 \\
\hline Instructor & $\begin{array}{l}\text { - } \text { Monitor progress of course } \\
\text { - } \text { Respond to email within a reasonable time } \\
\text { - } \text { Provide continuous feedback } \\
\text { - } \text { Participate in discussion } \\
\text { - Solve problems } \\
\text { ○ Technical } \\
\circ \text { Logistic } \\
\text { - } \text { Assess the students }\end{array}$ \\
\hline Tutor & $\begin{array}{l}\text { - Respond to students' emails } \\
\text { - Provide tutorials on productivity tools } \\
\text { - } \quad \text { Provide technical assistance }\end{array}$ \\
\hline
\end{tabular}

\section{The Resources Subsystem}

The resources subsystem includes what is referred to sometimes as white pages. These white pages may address the following issues:

- Additional notes on topics

- Procedures on:

- How to study in online courses

- Installation of different software required for successful use of learning recourses. For example, students need to install Quicktime so they can be able to view the videos.

- Instructions on navigating the OES.

- Slide presentation

- Course outline

- Links to other online resources

\section{The Implementation Subsystem}

The implementation subsystem entails the use of pedagogical and instructional strategies supporting learning. To that effect, the implementation subsystem is primarily concerned with processes. More specifically, the primary issue of pedagogy as a process for the online environment is to 
answer the question on how the knowledge contained in the subsystems will be used effectively to actually achieve learning. This knowledge includes:

- The instructors expertise of:

$\begin{array}{ll}\circ & \text { The content } \\ \circ & \text { The subject matter } \\ \circ & \text { Technology } \\ \circ & \text { Learning theories }\end{array}$

- The learner's present knowledge

- The knowledge contained in the documents found in the resources subsystem

- The knowledge contained in the implementation subsystem itself.

Considering the above, the fundamental instructional goal is the accurate transmission and reception of knowledge. Transmission and reception entails communication, and the communication characteristics describe the strategy. Communication is a strategy to knowledge acquisition. From this perspective, two interrelated forms of communication in OES can be identified: instructorlearner and learner-content communications. Instructor-learner can be between instructor and one or many learners (Kuehn, 1994). Learner-content communication can occur either via acquiring knowledge directly from the resources subsystem or by constructing meaning from dialog and reflection. These two types of learner-content communications reflect the cognitive processing and constructivism paradigm. The OES considers both instructor-learner and learner-content communications including both paradigms for the learner-content communications.

Table 2: Cognitive approach goals and communication strategies.

\begin{tabular}{|c|c|c|}
\hline & Instructional Goal & Communication Strategy \\
\hline 1 & $\begin{array}{l}\text { Present course content that hierarchically } \\
\text { structures sequence of information. }\end{array}$ & $\begin{array}{l}\text { 2D learning process: } \\
1^{\text {st }} \text { dimension: } \\
3 \text { step learning process. } \\
\text { Video/Audio } \rightarrow \text { Practice and Assessment } \rightarrow \\
\text { Discussion. } \\
2^{\text {nd }} \text { dimension: } \\
3 \text { level content hierarchy. } \\
\text { Information technology } \rightarrow \text { Data and informa- } \\
\text { tion resources management } \rightarrow \text { Information } \\
\text { systems. }\end{array}$ \\
\hline 2 & $\begin{array}{l}\text { Obtain student feedback to ensure accuracy } \\
\text { of understanding. }\end{array}$ & $\begin{array}{ll}- & \text { learner-teacher email } \\
\text { - } & \text { 1-way teacher-to-learner bulletin board }\end{array}$ \\
\hline 3 & $\begin{array}{l}\text { Provide opportunities for students to ques- } \\
\text { tion the instructor in order to ensure accu- } \\
\text { racy of understanding. }\end{array}$ & $\begin{array}{ll}\text { - } & \text { Forum } \\
\text { - } & \text { Hyperlinks }\end{array}$ \\
\hline 4 & $\begin{array}{l}\text { Create opportunities for students to commu- } \\
\text { nicate with each other in order to share their } \\
\text { understanding of course content. }\end{array}$ & $\begin{array}{ll}\text { - } & \text { content specific forum } \\
\text { - } & \text { eTalk (forum/discussion based) }\end{array}$ \\
\hline
\end{tabular}

There are eight primary instructional goals of the online education system, four of which are based on a cognitive processing approach (Table 2) and the other four are based on the construc- 
tivism approach (Table 3). A communication strategy is identified for each goal and implemented to maximize the goal attainment.

Table 3: Constructivism approach goals and communication strategies.

\begin{tabular}{|c|l|l|}
\hline & Instructional Goal & \multicolumn{2}{|c|}{ Communication Strategy } \\
\hline 1 & $\begin{array}{l}\text { Present a problem-solving situation in a re- } \\
\text { alistic context. }\end{array}$ & $\begin{array}{l}\text { Online, multimedia based tools for specific } \\
\text { and applicable components of the course }\end{array}$ \\
\hline 2 & $\begin{array}{l}\text { Provide opportunities for learners to col- } \\
\text { laboratively construct knowledge based on } \\
\text { multiple perspectives, discussion and reflec- } \\
\text { tion. }\end{array}$ & $\begin{array}{l}\text { - Web-based concept-based forum } \\
\text { - Online learning objects }\end{array}$ \\
\hline 3 & $\begin{array}{l}\text { Provide opportunities for learners to articu- } \\
\text { late and revise their thinking in order to en- } \\
\text { sure the accuracy of knowledge construc- } \\
\text { tion. }\end{array}$ & $\begin{array}{l}\text { - Concept-based forum } \\
\text { - Email }\end{array}$ \\
\hline 4 & $\begin{array}{l}\text { Create opportunities for the instructor to } \\
\text { coach and facilitate construction of student } \\
\text { knowledge. }\end{array}$ & $\begin{array}{l}\text { Analysis tools to streamline processes and } \\
\text { advance the technology so learners could } \\
\text { understand the content better. }\end{array}$ \\
\hline
\end{tabular}

\section{Technology Architecture}

The OES is a web-based learning management system that includes both learning elements and learning processes. The OES is not a portal-type website that acts as an 'information storage' and 'information retrieving' system, but rather it entails a flexible virtual environment with functionalities to manage course creation and learning processes. Figure 3 presents a conceptual level architecture of information and knowledge flow between the different technology components.

The back-end and front-end technologies used are to support the OES learning architecture tools that fall under three categories: (1) learning, (2) assessment, and (3) support. (1) Learning tools include a set of learning objects (with measurable learning outcomes), such as educational information system for enhanced learning (EISEL), virtual collaborative learning environment (VLE), project development environment (PDE), interactive computer aided learning (ICAL), and selfmaintained forum (SMF). (2) Assessment in the OES includes tools for formative assessment, summative assessment, self-assessment and peer-to-peer assessment. (3) Support to users is done through an innovative centralized question center with private and public zones that also operates in synchronous and asynchronous modes.

The OES is designed on object-classes. All components in the OES are classified into one of five types of objects: (1) role objects, (2) support objects, (3) reporting objects, (4) assessment objects, and (5) learning object. Each type of object has a unified front-end, which can be easily plugged into the OES by a relevant organizer and a similar back-end structure. The OES is a databasedriven system. The definition of each object is characterized by its meta-data properties in the common database. 
Professor | Teaching Assistant | Student

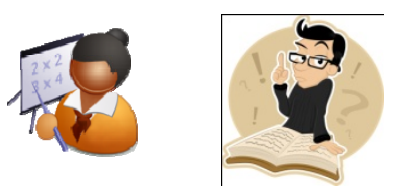

Tier 1: Interface Layer

Pedagogical

Configuration

$\mathrm{HCI}$

(Authoring)

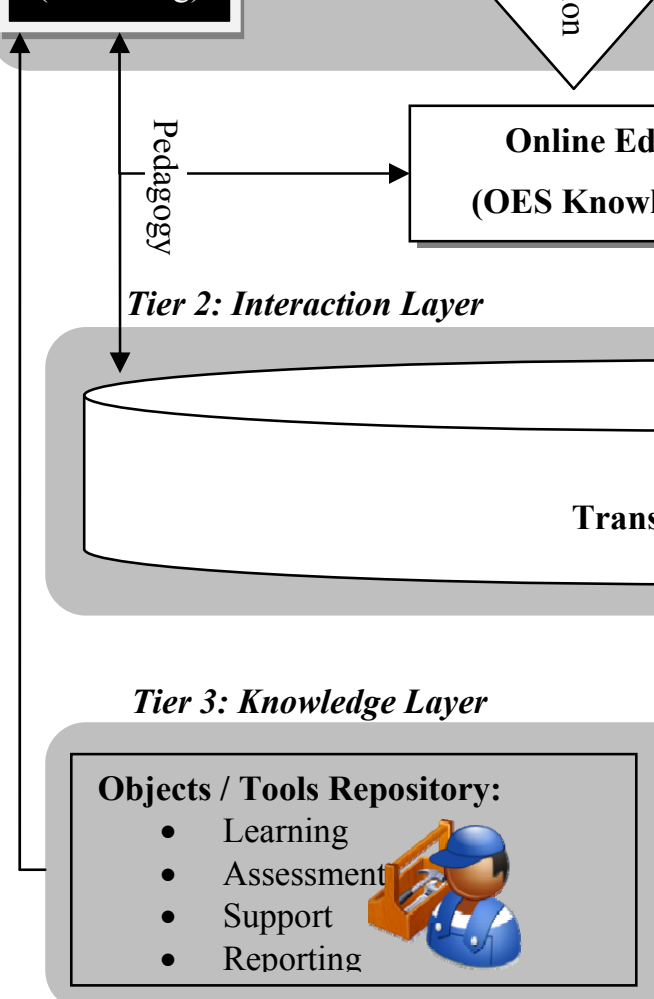

Transactions-Base

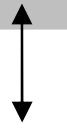

Delivery

$\mathrm{HCI}$

(Run-Time)

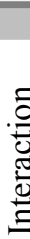

을
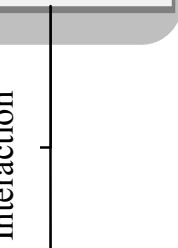

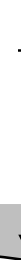
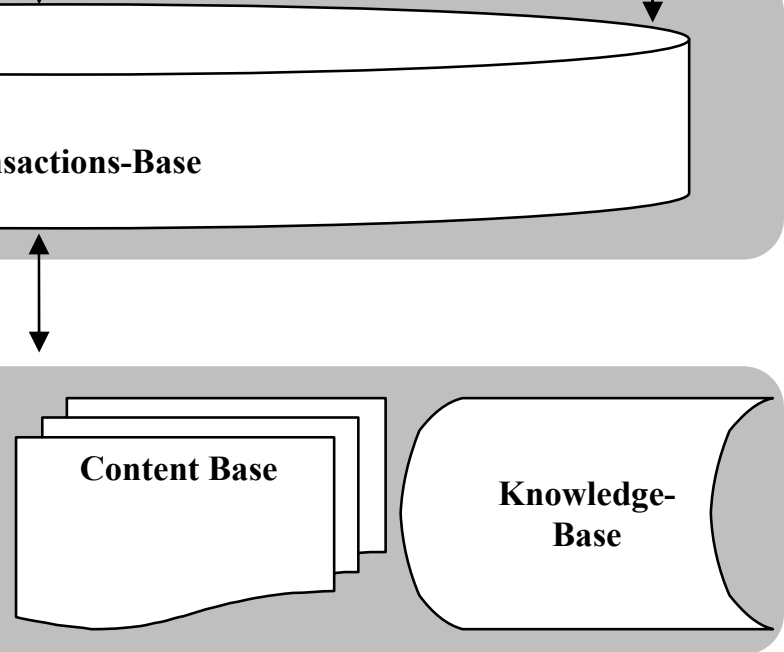

Figure 3: Conceptual knowledge creation and delivery framework. 
The OES is based on a three-tier architecture. Tier 1 is the interface level which constitutes the front-end. This front-end is common to all objects/tools. The second tier represents the transactional layer where all interactive and live data is stored for purpose of personalization, monitoring, and control. The third-tier is the knowledge tier which contains a repository of knowledge tables, specifications and meta-data of the different objects/tools, and content in different forms such as documents, video, and text. The description of the OES objects/tools is described as follows.

\section{OES management components:}

1. OES Management Center: OES Management Center is the central module of ELMS. It interacts with other modules and controls the data flow and execution orders between the modules.

2. Learning objects \& Learning objects organizer: Learning objects are designed for regular learning activities for students. Each learning object has the same database hierarchy.

3. Role objects \& organizer: Role objects refer to different roles in OES, including administrator, instructor, student, teaching assistant (TA), technical assistant and moderator.

4. Service objects $\&$ organizer: Service objects are a set of tools working with learning objects. They assist in the way learning objects behave, and provide a communication platform for users with different roles in OES. Communications between service objects and learning objects are accomplished by OES management center, service objects organizer, and learning objects organizer.

5. Reporting objects \& organizer: Reporting objects provide convenient tools to generate system reports for instructors, administrators and students.

\section{Learning tools/objects:}

6. EISEL: Learning with EISEL, students go through three system-guided steps: Pre-Test, Review resources, Practice related content, and Post-Test. This process is repeated for all the topics/concepts that the teacher has inputted into the system database.

7. VLE: VLE is a peer-to-peer collaborative testing system made up of three stages. In stage 1 , students are randomly assigned a task and asked to input their work into the system. In stage two, each student evaluates one of his/her peers' work created in stage 1 . The activity ends with an online test that all students take.

8. PDE: The Project Development Environment is a WIKI-based tool that allows the designer to setup a report structure for assignments, projects, or any other activity that is collaborative. The PDE allows the creation of groups of users to work together on a specific project/assignment. At the end, the deliverables are submitted and evaluated online and feedback is provided instantaneous.

9. SMF: The Self Maintained Forum is an open source phpbb-forum based application, which has been modified to allow for peer review of posts. Based on basic consensus logic, posts are either sent to a garbage-bin or pushed to the top screen.

10. ICAL: An Interactive Computer-Aided Learning tool is used to enhance student cognitive abilities and content learning via interactive sessions. The student interacts with a computer agent (CA). The CA is based on some basic inferences and rules. Briefly, three types of question are available: multiple choice, true or false, and fill in the blanks. ICAL is based on using basic domain concepts. For each concept, there would be 10 question of each type where the questions are inter-related. This allows the student to establish con- 
nections between meaning, syntax and ontology. The CA randomizes the type of question then randomizes the question in the category identified and which is then presented to the student. The student answers the question, receives a right or wrong notation and another randomized question is asked immediately after. This goes on until the student achieves a certain average or stops the session to continue later.

\section{Support tools/objects:}

11. DQC: The dynamic question center is an asynchronous environment where students ask questions that they have to categorize. Based on the category of question, different teaching assistants (content, technical, professor, etc.) are assigned to the categories to answer. The questions can be labeled private (only student and professor sees) or public (everybody sees the question and answer). Question-answer sets can also be rated for importance, which controls the first page content view. Filters are easily available on the first page.

12. VTutor: Vtutor is the synchronous part of the support tools. Using VTutor office hours, unstructured tutorials and structured sessions can be held and even recorded.

13. CRT: The Course Reporting Tool is a knowledge-base connected to an email server which sends messages and reports based on rules. The CRS runs in real-time throughout the semester.

\section{Assessment tools/objects:}

14. FAT: The Formative Assessment Tool is a database driven engine that contains questions of different types such as multiple choice, true or false, fill in the blanks, and essay. The engine can be configured in various ways to support different types of learning. With FAT, questions are generated and presented to the user in a random or specific fashion. Feedback is also provided in different interactive, comparative, and final forms.

15. SAT: The Summative Assessment Tool is similar to FAT and uses the same engine. What is different in SAT are the pre- and post-reflective questions that measure students' preparedness, perceptions, and expectations of the exam.

16. SeAT: The Self Assessment Tool includes activities where students get the opportunity to evaluate their own work.

17. PAE: The Peer Assessment Environment is a web space where students post their work and via the use of pre-specified rubriques evaluate each others' work.

All these tools can be mixed and matched depending on the course requirements, pedagogical scheme, and the professor's perspectives of the course.

\section{Assessment Methodology}

As the higher education industry continues its attempts to develop, integrate, and increase participation in fully online courses, the pressure to study the efficiency of using OESs and its impact on learning increases as well. Although the body of literature is large and growing, the subset of literature dealing with student attitudes towards technology of online computer mediated learning is small (Saade, 2007; Saade and Bahli, 2005; Valenta, Therriault, Dieter, \& Mrtek, 2001). The theory of planned behavior (TPB) (Ajzen, 1985) and the technology acceptance model (TAM) can be used to explain behavior towards OESs. The historical antecedent of the TPB and TAM lies in the theory of reasoned action (Fishbein \& Azjen, 1975). 
The TRA identifies the proximal determinants of behavior as the strength of an intention whether or not to engage in that behavior. In turn, antecedents to behavioral intentions were identified from two cognitive processes, namely, attitudes and behavioral norms. Attitudes towards a behavior can be measured from beliefs about the behavior under consideration and valences attached to those beliefs. Behavioral norms include the influence that salient others (such as parents and friends whose opinions are important to the individual) would have on an individual to engage or not in the behavior under consideration and the individuals' motivation to comply (Bozionelos \& Bennett 1999). Intentions accurately predict behavior only when the behavior is under the individuals' volitional control (Fishbeing \& Ajzen 1975). To account for such factors, a third variable, perceived behavioral control (PBC) was added in the TRA (Ajzen, 1985; Ajzen \& Madden, 1986).

\section{Theory of Planned Behavior}

The new addition of the PBC construct to the TPB model (which is absent in the TAM) has been sparingly tested and used in IS research (Benham \& Reymond, 1996; Kallol, Hart, \& Cerveny, 2002). Perceived behavioral control reflects the successful performance of an intended behavior, which is contingent on the person's control over the factor that may prevent it and takes into account realistic constraints that may exist (Ajzen, 1988; Karahanna, Straub, \& Chervany, 1999).

Within the context of the present work, the theory of planned behavior presented in Figure 4 posits that behavioral intentions to use an online educational system are guided by three factors:

1. the individuals' favorable or unfavorable attitude towards an OES which is their beliefs about the likely outcome(s) of the behavior and the evaluations of the(se) outcome(s),

2. subjective norm (which can be viewed as social pressure) which includes beliefs about the expectations of others and motivation to comply with these expectations, and

3. perceived behavioral control which entails the beliefs about the presence of factors that may facilitate or impede performance of the behavior and the perceived power of these factors.

Belief that they will use the OES successfully.

Perceptions of colleague's opinions on using the OES.

Perception that one possesses the skills and abilities to successfully perform required tasks.

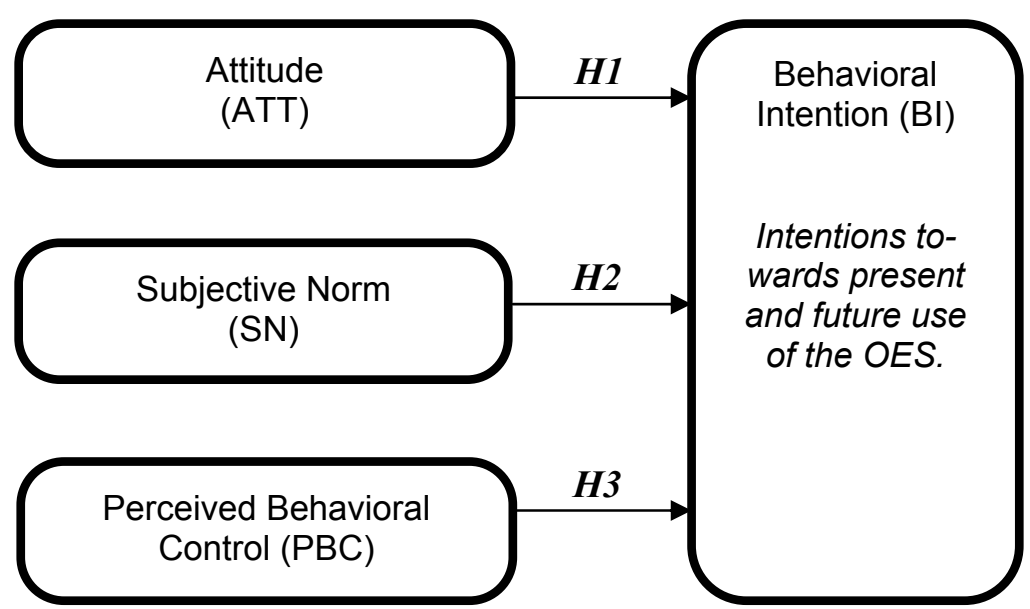

Figure 4. The Theory of Planned Behavior. 
It is clear that beliefs and associated evaluations lead to intentions. With respect to the use of OES, attitudes (or behavioral beliefs) of an individual might be his/her beliefs that using the EOS the individual can successfully complete the tasks and course requirements. Subjective norm (or normative beliefs) could be the individual's perception of his/her colleagues' opinions on using OES and experiences with taking an online course. PBC (or control beliefs) is the individual's perception that he/she possess the skills, resources, and tools to successfully perform the required tasks.

Therefore, based on the above discussion, we hypothesize:

H1: Attitude has a positive effect on behavioral intention to use the OES.

H2: Subjective Norm has a positive effect on behavioral intention to use the OES.

H3: Perceived Behavioral Control has a positive effect on behavioral intention to use the OES.

\section{The Technology Acceptance Model}

Studying the acceptance of information technology (IT) has been the focus of many Information System (IS) researchers. The research efforts have been in the building of theories that can predict the determinant factors of IT acceptance (Lee, Park, \& Ahn, 2001). The Technology Acceptance Model (TAM) developed by Davis, Bagozzi, and Warshaw (1989) is the most widely used model for IT acceptance and adoption and has received considerable attention in IS research.

The TAM (Davis, 1986, 1989) which was adapted from the Theory of Reasoned Action (Fishbein $\&$ Ajzen, 1975) identifies four variables and the relationships between them. These variables are given in Figure 5 and the relationships between the variables explain a user's acceptance of Information Technology (IT).

Perceptions of usefulness of the OES to help in better performance.

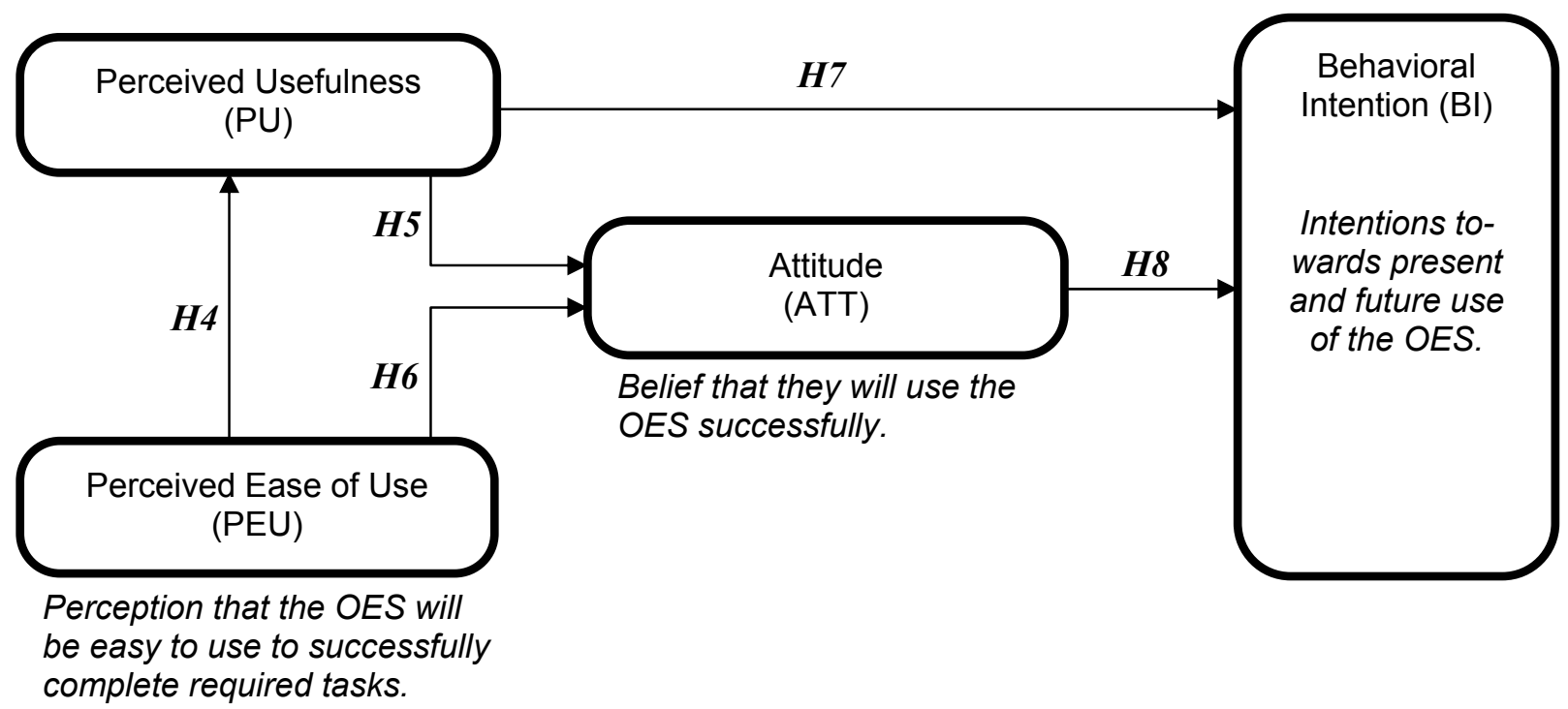

Figure 5. The Technology Acceptance Model

Technology acceptance is defined as "an individual's psychological state with regard to his or her voluntary or intended use of a particular technology" (Gattiker, 1984). 
Perceived usefulness is defined as "the degree to which a person believes that using a particular system would enhance his or her job performance" (Davis 1989). It has been shown that perceived usefulness has a significant influence on the use of a system because of the individual's belief in the existence of a use-performance relationship (Agarwal \& Karahanna, 2000; Saadé, 2007).

Perceived ease of use can be described as "the degree to which a person believes that using a particular system would be free of effort" (Davis, 1989). As such, ease of use represents the facility of interaction between the individual and the target system. Previous research has demonstrated that individuals are more accepting to use a new technology if they perceive that it is easy to use (Adams, Nelson, \& Todd, 1992).

Attitude has been identified as an essential intention determinant to behavioral intention, as described by the well established theory of reasoned action. The TRA is an intention-based theory, which identifies beliefs to influence attitude, which in turn shapes intention, hence behavior (Chau \& Hu, 2002; Fishbein \& Ajzen, 1975).

A software or information system that is perceived to be easier to use than another has better chances of being accepted (Davis, 1989). TAM postulates that a user's perceived usefulness of a system and his/her attitude towards using it (determined by perceived usefulness and perceived ease of use) determines behavioral intention to use the system (Figure 5) (Davis et al. 1989). This is supported by various theories and models such as expectancy theory, self-efficacy theory, costbenefit research, innovation research, and the channel disposition model (Chau, 1996). If a user's behavior is the intention to use the system, then this will lead to actual use of the system.

In the TAM, perceived ease of use was posited to influence behavioral intention directly and indirectly via perceived usefulness. This indirect causal effect is justified, arguing that by having lower cognitive burden (implying that the system is more easy to use, hence less effort is required to execute tasks) while using the system, more of the cognitive resources are then made available to attention.

Perceived usefulness is influenced by perceived ease of use, such that both constructs are in turn influenced by external variables. These external variables may include system features, training, documentation, and user support (Chau, 1996; Davis et al., 1989).

Therefore, based on the above discussion, we hypothesize:

H4: Perceived Ease of Use has a positive effect on Perceived Usefulness of the OES.

H5: Perceived Usefulness has a positive effect on Attitudes towards the OES.

H6: Perceived Ease of Use has a positive effect on Attitudes towards the OES.

H7: Perceived Usefulness has a positive effect on Behavioral Intention to use the OES.

H8: Attitudes has a positive effect on Behavioral Intention to use the OES.

\section{The Internet, Learning and TAM}

Instruction over the internet is perceived by many researchers to be a significant breakthrough in teaching and learning (Gupta \& Bostrom, 2009; Saadé \& Galloway, 2005; Saadé \& Kira, 2006; Wan, Wang, \& Haggerty, 2008). This is attributed to the fact that the internet technology allows and facilitates the exchange of information and expertise while providing opportunities for types of learners in remote and disadvantaged locations (Saadé \& Bahli, 2005, Webster, \& Hackley, 1997). Contrary to this perception, one finds many educators and trainers: 
- Who do not believe the usefulness of online instruction to actually solve difficult teaching and learning problems (Conlon, 1997);

- Who are concerned about the many barriers that negatively influence effective online teaching and learning including (Brandt, 1996; Johnson, Aragon, Shaik, \& Palma-Rivas, 2000):
$\circ \quad$ The changing nature of technology
○ The complexity of networked systems
$\circ \quad$ The lack of stability in online learning environments and
- The limited understanding of how much instructors and students need to know to successfully participate

The internet allows educators to provide learners with new and innovative virtual environments in an attempt to stimulate and enhance the learning process (Brown, 2002; Saadé \& Huang, 2009; Saadé \& Kira, 2008). Internet or web technologies are important to the educational process because they support sophisticated manipulation of information, facilitates and enhance communications between instructor and learners as well as among learners, thereby promoting collaborative work, and they provide tools to encourage creativity and initiative.

The agglomeration of the internet and learning creates a multidimensional problem from a research as well as applicability point of view. The five most important issues produced by the internet-learning mix include:

- The learning environment: What learning principle does the web site support (collaborative learning, learner-centered, constructivism, situational learning ...)

- The learning tools used: That addresses the aspects of communications (such as chat rooms, bulletin boards, and discussion), videos, animation, and practice problems and quizzes.

- The use of Learning-oriented objects: This includes decision support systems for learning such as teaching agents, expert systems, adaptive learning systems, internet mediated agents, and simulation systems.

- Content: Educators: not only do they have to address the amount of content to include as part of the requirements for a course but also how it will be delivered online.

- Support: This issue acknowledges the fact that not all learners learn alike. The majority of learners are not accustomed to learning over the internet. Learners should be given support and provided instructions on how to learn over the internet.

- The effectiveness of internet learning: This includes proper assessment and evaluation of internet learning with two regards: learner satisfaction, and learner acceptance.

With respect to learning over the internet, the aim of this study is to gain insight into how learners perceive the use of internet-based technology for their learning. When the web-based learning environment was introduced, the problems were technology related and included issues of access, connection, internet familiarity, and lack of independent learning (Chin, 1999). As technology advanced, the problems shifted towards the learner side of the court. While learners had gained space and time flexibility, many still felt isolated and de-motivated. "Students are still working to come to grips with a new and difficult way of learning. They exemplify the concern by asking for more incentive, more time, more structure, and more guidance" (Hedberg, Harper, \& CorrentAgostinho, 1998).

Although online courses have been growing significantly in recent years, their capabilities and efficacy have yet to be fully studied and understood. Most of these efforts have been in the devel- 
opment of the web-based environment for learning while the examination of the quality and effectiveness of such web sites and technology implementation on learning were neglected. As it stands today, relatively little empirical knowledge about internet-based education (instruction and learning) has been published, and the need for research in this area is not only timely, but imperative (Johnson et al., 2000, Saadé and Kira, 2009).

Few experimental studies have assessed the effectiveness of online instruction. One study showed that instruction provided online has resulted in improved performance (Schutte, 1997). Another study showed that students taking an internet-based course had student attitude ratings equal to those of the traditional classroom (LaRose, Gregg, \& Eastin, 1998).

Satisfaction is related to perceptions of being able to achieve success and feelings about the achieved outcomes (Keller, 1988). From this perspective, several studies have explored student satisfaction with internet-based courses (Johnson et al., 2000; Saadé \& Kira, 2008). Some of the findings are:

- Students were satisfied with online instruction because it provided flexibility and responsiveness to their learning requirements and expectations (Enockson, 1997).

- Students' satisfaction is positively impacted when (a) the technology is transparent, reliably and convenient, (b) the course supports learner-centered strategies, (c) the instructor is a facilitator and (d) flexibility.

- Student satisfaction depends more on the quality and effectiveness of the instructor and the instruction than on the technology.

Studies of learner satisfaction are typically limited to one-dimensional post-training perceptions of learners (Johnson et al., 2000). As mentioned earlier, acceptance and satisfaction of an internet-based learning environment is multidimensional and includes a wide variety of critical variables. These variables include perceptions, beliefs, attitudes, learners' characteristics, and level of involvement with the online course material. If internet-based learning environments are to benefit students then it is important that from the student's perspective they are not seen to be overly complex (Brown, 2002). Students' acceptance of such technologies depends highly on their perceived usefulness and perceived ease of use. The introduction of internet-based learning environments may hinder the learning process if the technology is perceived as being complex and not useful to enhanced performance, and thus prove to be a distraction to learning (Helmi, Haynes, \& Maun, 2000).

\section{Methodology}

\section{Study Context and Participants}

The approach taken to test the relationships implied in the proposed research model and the hypotheses was a case study and a survey methodology was used for data collection. The beliefs of students registered in an introductory undergraduate management information systems on-line course at Concordia University, John Molson School of Business, Department of Decision Sciences and MIS were surveyed after an orientation session was given.

The on-line course was designed based on the cognitive and constructivist approaches to learning. The on-line course was developed for the web, and students were able to use the learning tool anywhere, anytime. The system provides guidance and monitors students' efforts with respect to three variables: time spent on different parts of the system, chapters-based assessment scores, and participation in concept-based forum. Besides the fact that internet is widely used among students, the selection of the web to implement the learning tool is appropriate (Agarwal \& Karahanna, 2000): 
- The technology is available from many locations around the campus, friends, internet cafes and homes (thus access would not count as a barrier to the usage of the technology) and

- More and more courses are using the web as the platform to post static course information and material and provide the students with learning objects targeted at helping them learn the required topics from using different approaches.

The course is required as part of their undergraduate bachelors degree. Students in the course were majoring in one of the following: finance, accounting, MIS, human resources, international business, operations management, and administration. Students were presented the survey questionnaire on-line and were given the choice to participate. They were informed that the questionnaire would be used to measure their perceptions of the online course, which may help improve the design of the course and delivery of content in future sessions. They were instructed to respond as candidly as possible and to the best of their knowledge.

Out of 168 students who registered for the course, 114 completed the survey. Since the survey was on-line, the 114 participants completed the survey within a period of 3 weeks. The implication of this is that students had a chance to use the online educational system prior to completing the survey.

\section{The Sample}

Table 4 presents the item scales used for the questions and corresponding mean and standard deviations. The student's sample represented a group:

○ with an average age close to 24 years and work experience approximately 1year;

o which claims to be somewhat knowledgeable in computers and rates their experience with at least one Microsoft product as high; and

o that has been using the internet for about one year and uses it around 1.5 hours a day;

Therefore, based on the students' experiences with computers, we expected that they are likely to possess well-formed beliefs and positive perceptions about information technologies.

Table 4. Scales used for questions

\begin{tabular}{|l|c|c|c|c|c|c|c|}
\multicolumn{1}{c|}{$\begin{array}{l}\text { Scale } \rightarrow \\
\text { Question }\end{array}$} & $\mathbf{1}$ & $\mathbf{2}$ & $\mathbf{3}$ & $\mathbf{4}$ & $\mathbf{5}$ & Mean & S.D. \\
\hline $\begin{array}{l}\text { Knowledge about com- } \\
\text { puters. }\end{array}$ & V.K. & S.K. & N. & S.U. & V.U. & 2.45 & 1.01 \\
\hline Work experience. & $<6 \mathrm{~m}$ & $6 \mathrm{~m}-1 \mathrm{yr}$ & $1-2 \mathrm{yrs}$ & $2-5 \mathrm{yrs}$ & $>5 \mathrm{yrs}$ & 2.28 & 1.13 \\
\hline Time using the internet. & $<6 \mathrm{~m}$ & $6 \mathrm{~m}-1 \mathrm{yr}$ & $1-2 \mathrm{yrs}$ & $2-5 \mathrm{yrs}$ & $>5 \mathrm{yrs}$ & 2.35 & 0.64 \\
\hline Daily internet usage. & $<15 \mathrm{~min}$ & $15 \mathrm{~min}-1 \mathrm{hr}$ & $1 \mathrm{hr}-2 \mathrm{hrs}$ & $2-5 \mathrm{hrs}$ & $>5 \mathrm{hrs}$ & 2.90 & 1.01 \\
\hline Age group. & $<18 \mathrm{yrs}$ & $18-22 \mathrm{yrs}$ & $22-24 \mathrm{yrs}$ & $\begin{array}{c}24- \\
26 \mathrm{yrs}\end{array}$ & $>26 \mathrm{yrs}$ & 3.26 & 1.34 \\
\hline $\begin{array}{l}\text { Knowledge of the English } \\
\text { language. }\end{array}$ & V.H. & H. & N. & L. & V.L. & 2.12 & 0.92 \\
\hline $\begin{array}{l}\text { Experience with at least } \\
\text { one of Microsoft products. }\end{array}$ & V.H. & H. & N. & L. & V.L. & 2.24 & 0.84 \\
\hline Mother tongue. & English & French & Arabic & Chinese & Other & 3.00 & 1.64 \\
\hline
\end{tabular}

$\mathrm{K} .=$ Knowledgeable; $\mathrm{U} .=$ Unknowledgeable; $\mathrm{m}=$ months; $\mathrm{yrs}=$ years; $\mathrm{V}=\mathrm{Very} ; \mathrm{H}=$ High;

$\mathrm{L}=$ Low; $\mathrm{N}=$ Neutral; $\mathrm{S}=$ Somewhat. 


\section{Operationalization of Research Variables}

All research variables were measured using a five-point Likert-type scale with anchors from "Strongly disagree" to "Strongly agree." Items used to operationalize the constructs (Table 5) were adopted from different relevant prior research work. Specific items for perceived usefulness and ease of use were adapted from Davis (1989), which were extensively validated. Items for behavioral intentions were based on Ajzen and Fishbein (1980). Finally, items for subjective norm and perceived behavioral control were adapted from Mathieson (1991).

Table 5. Question items used in the study.

\begin{tabular}{|c|c|c|}
\hline Construct & Item & Measure \\
\hline \multirow[t]{4}{*}{ Perceived Usefulness (PU) } & PU1 & $\begin{array}{l}\text { I feel that using the OES will improve my performance in the } \\
\text { course. }\end{array}$ \\
\hline & PU2 & I think that using the OES will improve my productivity. \\
\hline & PU3 & $\begin{array}{l}\text { I think that using the OES will enhance my effectiveness in the } \\
\text { course. }\end{array}$ \\
\hline & PU4 & I find the OES useful for the course. \\
\hline \multirow[t]{4}{*}{ Perceived Ease of Use (PEU) } & PEU1 & I think that learning to navigate the OES will be easy for me. \\
\hline & PEU2 & $\begin{array}{l}\text { I think that I will find it easy to get the OES to do what I want it } \\
\text { to do. }\end{array}$ \\
\hline & PEU3 & $\begin{array}{l}\text { I think that it would be easy for me to become skillful at using } \\
\text { the OES. }\end{array}$ \\
\hline & PEU4 & I think that I will find the OES easy to use. \\
\hline \multirow[t]{3}{*}{ Attitude (ATT) } & ATT1 & Taking online courses is a good idea. \\
\hline & ATT2 & Taking online courses would be pleasant. \\
\hline & ATT3 & Taking online courses would be beneficial to me. \\
\hline \multirow[t]{2}{*}{ Intention (I) } & IU1 & I intend to take more courses using an OES in the future. \\
\hline & IU2 & I intend to show others this OES. \\
\hline \multirow[t]{2}{*}{ Subjective Norms (SN) } & SN1 & $\begin{array}{l}\text { Students who influence my behavior think that I should take } \\
\text { online courses. }\end{array}$ \\
\hline & SN2 & $\begin{array}{l}\text { People who are important to me think that I should take online } \\
\text { courses. }\end{array}$ \\
\hline \multirow{3}{*}{$\begin{array}{l}\text { Perceived Behavioral Control } \\
\text { (PBC) }\end{array}$} & PBC1 & I think that I will be able to use all the components of the OES. \\
\hline & PBC2 & $\begin{array}{l}\text { I think that using the components of the OES would be entirely } \\
\text { within my control. }\end{array}$ \\
\hline & PBC3 & $\begin{array}{l}\text { I think that I will have the resources, the knowledge and the abil- } \\
\text { ity to make use of all the components of the OES. }\end{array}$ \\
\hline
\end{tabular}

\section{Assessment of Measurement Model}

Psychometric properties of the scales are assessed in terms of item loadings, discriminant analysis, and internal consistency. Reliabilities of individual items are assessed by examining the loadings of the items on their respective constructs. These loadings should be higher than 0.5 , following the criterion indicated by Rivard (1988) to indicate that significant variance shared between each item and the construct.

Table 6 presents the confirmatory factor analysis of the research constructs. Descriptive statistics and reliability assessment are shown in Table 7. As can be seen from the confirmatory factor 
analysis results (Table 6), all items exhibit high loadings, well above the criteria of 0.5 . Without exceptions, all items load more highly on their own construct than on other constructs. The loadings show a clear discriminant and convergent validity for all constructs. Furthermore, all constructs in the model exhibit good internal consistency as evidenced by the reliability coefficient given in Table 7 . The reliability coefficient for internal consistency for the six constructs is more than adequate with values above 0.9 with the exception of intention to use $(0.8)$.

Table 6. Results of Factor Analysis

\begin{tabular}{|llllllc|}
\hline & PEU & PU & PBC & ATT & SN & I \\
\hline PEU1 & $\mathbf{0 . 7 5 6}$ & 0.236 & 0.385 & 0.252 & 0.070 & 0.006 \\
\hline PEU2 & $\mathbf{0 . 8 0 5}$ & 0.258 & 0.297 & 0.203 & 0.145 & 0.096 \\
\hline PEU3 & $\mathbf{0 . 8 2 1}$ & 0.252 & 0.150 & 0.169 & 0.005 & 0.102 \\
\hline PEU4 & $\mathbf{0 . 7 3 3}$ & 0.357 & 0.312 & 0.158 & 0.099 & 0.183 \\
\hline PU1 & 0.238 & $\mathbf{0 . 8 2 2}$ & 0.093 & 0.255 & 0.140 & 0.091 \\
\hline PU2 & 0.193 & $\mathbf{0 . 8 4 2}$ & 0.181 & 0.146 & 0.072 & 0.004 \\
\hline PU3 & 0.219 & $\mathbf{0 . 8 6 8}$ & 0.092 & 0.194 & 0.045 & 0.125 \\
\hline PU4 & 0.292 & $\mathbf{0 . 6 4 2}$ & 0.012 & 0.436 & 0.070 & 0.085 \\
\hline SN1 & 0.146 & 0.129 & 0.091 & 0.116 & $\mathbf{0 . 8 9 5}$ & 0.089 \\
\hline SN2 & 0.004 & 0.074 & 0.027 & 0.172 & $\mathbf{0 . 8 6 8}$ & 0.255 \\
\hline A1 & 0.171 & 0.249 & 0.212 & $\mathbf{0 . 8 4 0}$ & 0.131 & 0.152 \\
\hline A2 & 0.266 & 0.272 & 0.268 & $\mathbf{0 . 7 2 4}$ & 0.156 & 0.113 \\
\hline A3 & 0.192 & 0.323 & 0.156 & $\mathbf{0 . 7 8 6}$ & 0.144 & 0.066 \\
\hline I1 & 0.314 & 0.034 & 0.244 & 0.376 & 0.217 & $\mathbf{0 . 7 3 2}$ \\
\hline I2 & 0.142 & 0.342 & 0.240 & 0.100 & 0.083 & $\mathbf{0 . 7 5 7}$ \\
\hline PBC1 & 0.154 & 0.063 & $\mathbf{0 . 8 6 5}$ & 0.130 & 0.003 & 0.240 \\
\hline PBC2 & 0.353 & 0.036 & $\mathbf{0 . 7 5 2}$ & 0.236 & 0.145 & 0.193 \\
\hline PBC3 & 0.429 & 0.116 & $\mathbf{0 . 7 7 6}$ & 0.219 & 0.013 & 0.056 \\
\hline & & & & & & \\
\hline
\end{tabular}

To assess the reliability of the latent variable estimated by PLS, the composite reliability coefficients $\rho_{\mathrm{c}}$ suggested by Werts, Joreskog, and Linn (1973) were calculated and presented in Table 7. The composite reliability $\rho_{c}$ is calculated using the following formula:

$\rho_{c}=\frac{\left(\sum \lambda_{i}\right)^{2} \operatorname{var} F}{\left(\sum \lambda_{i}\right)^{2} \operatorname{var} F+\sum \Theta_{i i}}$

where $\lambda_{\mathrm{i}}, \mathrm{F}$ and $\Theta_{\mathrm{ii}}$ are the factor loadings, factor variance and unique/error variance respectively. Li is given in table $9, \mathrm{~F}$ is set to 1 and

$\Theta_{i i}=1-\lambda_{i}^{2}$ 
Table 7. Research Constructs Descriptive Statistics and Reliability Assessment

\begin{tabular}{|lcccc|}
\hline \multicolumn{1}{|c}{ Variables } & \# of items & Rho & Mean & S.D. \\
\hline Perceived Usefulness (PU) & 4 & 0.93 & 3.9 & 0.79 \\
\hline Perceived Ease of Use (PEU) & 4 & 0.95 & 3.6 & 0.91 \\
\hline Attitude (ATT) & 3 & 0.94 & 3.8 & 0.85 \\
\hline Subjective Norm (SN) & 2 & 0.92 & 2.6 & 0.76 \\
\hline Perceived Behavioral Control (PBC) & 3 & 0.94 & 3.8 & 0.79 \\
\hline Intention to Use (I) & 2 & 0.80 & 3.6 & 0.91 \\
\hline
\end{tabular}

To evaluate discriminant validity, Fornell and Larcker (1981) suggested a comparison between the average extracted variance of each factor and the variance shared between the constructs (the squared correlations between the constructs). It is expected that the loadings of all items within a construct should be high on that construct, indicating high convergent validity, and low on the other ones, displaying high discriminant validity. The first characteristic indicates that they share a lot of variance with their construct and the latter that they are independent from the other constructs. Cross-loadings of items are reflected in Table 8.

Table 8. Inter-Construct Correlations

\begin{tabular}{|lcccccc|}
\hline & ATT & PU & PEU & I & SN & PBC \\
\hline ATT & $\mathbf{0 . 9 2}$ & & & & & \\
\hline PU & 0.62 & $\mathbf{0 . 8 9}$ & & & & \\
\hline PEU & 0.57 & 0.56 & $\mathbf{0 . 9 2}$ & & & \\
\hline I & -0.61 & -0.46 & -0.64 & $\mathbf{0 . 8 5}$ & & \\
\hline SN & 0.45 & 0.30 & 0.27 & -0.33 & $\mathbf{0 . 9 2}$ & \\
\hline PBC & 0.52 & 0.37 & 0.74 & -0.77 & 0.20 & $\mathbf{0 . 9 2}$ \\
\hline
\end{tabular}

\section{Assessment of Structural Model}

The assessment of the structural model was done using the PLS approach using PLS Graph (Chin, 1999). The estimated path effects are given along with their degree of significance. The paths are interpreted as standardized beta weights in a regression analysis. A bootstrapping procedure was used to assess the level of significance of the paths computed by PLS. T-values were computed from a series of PLS evaluations made against several partitions of the data set. The results of the PLS run with the overall sample ( $\mathrm{n}=114$ observations) are shown in Figure 6 . All of the constructs were modeled as reflective and were measured using multiple indicators rather than summative scales. The outer model loadings of all the items on their respective constructs are shown in Table 9.

Perceived usefulness and attitude together explain $38 \%$ of intentions, while social norm, perceived behavioral control, and attitude explain 58\%. The theory of planned behavior explains intentions around $50 \%$ better. Perceived usefulness and perceived ease of use account for $46 \%$ of the variance in attitude. It is evident from Figure 6 that PLS results provide stronger support for the theory of planned behavior than those of the technology acceptance model. 
Hypotheses 1 and 6, which posited that perceived usefulness and social norm would influence intentions, were not supported. Hypothesis $2(\mathrm{ATT} \rightarrow \mathrm{I}=-0.232)$ is marginally supported. Hypotheses $3,4,5$, and 7 are strongly supported. Summarized results for the hypotheses tests are shown in Table 10.

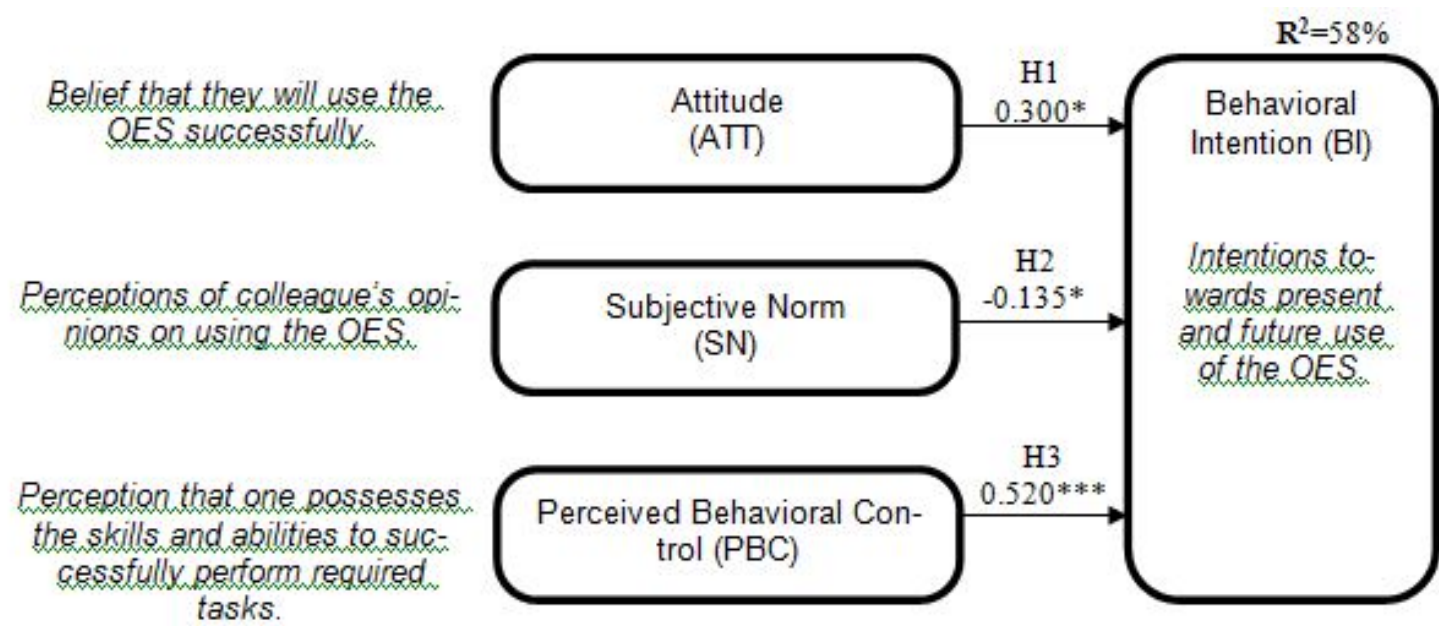

Figure 6a: Theory of Planned Behavior Model

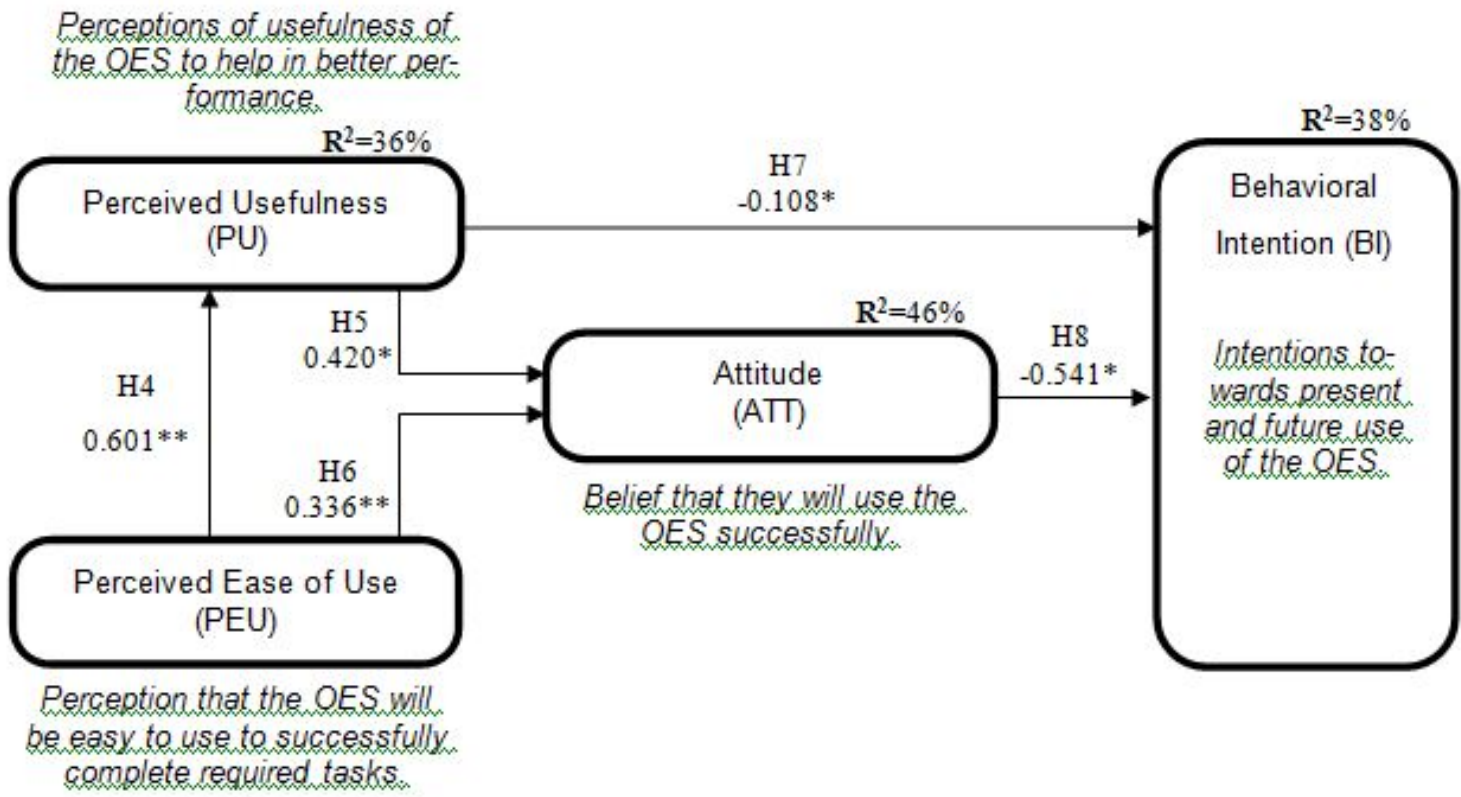

Figure 6b: Technology Acceptance Model 


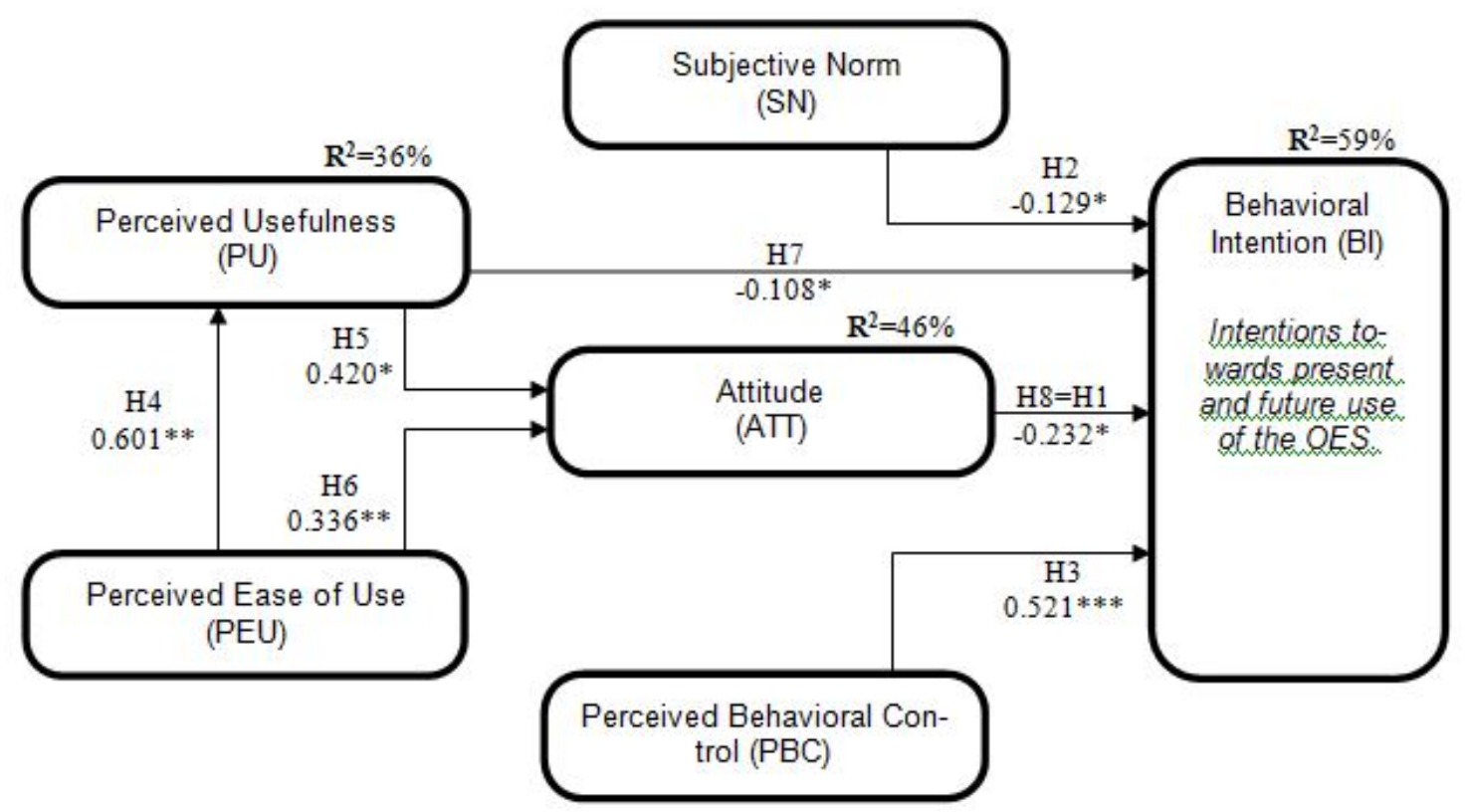

Figure 6c: Integrated TAM+TPB Model $p<0.05=* ; p<0.01=* * ; p<0.001=* * *$

Figure 6: Model parameters for the research model.

Table 9. PLS outer model loadings

\begin{tabular}{|l|c|c|}
\hline \multicolumn{1}{|c}{ Construct } & Item & $\begin{array}{c}\text { PLS Outer } \\
\text { Model Loading }\end{array}$ \\
\hline Perceived Usefulness (PU) & PU1 & 0.898 \\
\cline { 2 - 3 } & PU2 & 0.871 \\
\cline { 2 - 3 } & PU3 & 0.915 \\
\cline { 2 - 3 } & PU4 & 0.846 \\
\hline Perceived Ease of Use (PEU) & PEU1 & 0.918 \\
\cline { 2 - 3 } & PEU2 & 0.942 \\
\cline { 2 - 3 } & PEU3 & 0.855 \\
\cline { 2 - 3 } & PEU4 & 0.918 \\
\hline Attitude (ATT) & ATT1 & 0.940 \\
\hline & ATT2 & 0.894 \\
\hline & ATT3 & 0.897 \\
\hline Intention (I) & IU1 & 0.814 \\
\cline { 2 - 3 } & IU2 & 0.868 \\
\hline Subjective Norms (SN) & SN1 & 0.901 \\
\cline { 2 - 3 } & SN2 & 0.917 \\
\hline Perceived Behavioral Control (PBC) & PBC1 & 0.887 \\
\cline { 2 - 3 } & PBC2 & 0.879 \\
\cline { 2 - 3 } & PBC3 & 0.928 \\
\hline
\end{tabular}


Table 10. Summary of Hypotheses Tests - Integrated Model

\begin{tabular}{|l|c|c|c|}
\multicolumn{1}{|c|}{ Hypothesis } & Strength/Direction & p & Supported \\
\hline H1: ATT $\rightarrow$ I & W/- & $*$ & Not Supported \\
\hline H2: SN $\rightarrow$ I & W/- & $*$ & Not Supported \\
\hline H3: PBC $\rightarrow$ I & S/+ & $* * *$ & Supported \\
\hline H4: PEU $\rightarrow$ PU & S/+ & $* *$ & Supported \\
\hline H5: PU $\rightarrow$ ATT & S/+ & $*$ & Supported \\
\hline H6: PEU $\rightarrow$ ATT & M/+ & $* *$ & Supported \\
\hline H7: PU $\rightarrow$ I & N/- & $*$ & Not Supported \\
\hline H8: ATT $\rightarrow$ I & W/- & Not Supported \\
\hline
\end{tabular}

Strength: $\mathrm{N}=$ None; $\mathrm{W}=$ Weak; $\mathrm{M}=$ Moderate; $\mathrm{S}=$ Strong (Based on threshold $=0.30$ for path coefficient.)

\section{Limitations}

The technology acceptance model is a simple model that is useful in predicting attitude and intention, as has been observed many times in research (Legris, Ingham, \& Collerette, 2003). The theory of planned behavior is an important and more general model where social norm and perceived behavioral control are introduced. Among these constructs, perceived behavioral control was shown to be the most significant. This is in agreement with the 1178 participants study by Karahanna et al. (1999). In this study, the addition of the perceived behavioral control construct provided further insights and increase in the explained variance. This study comes to the same conclusion and further confirms the finding for an online learning context.

We acknowledge also that implications are confined to the limits of their interpretation and must be acknowledged. We address the limitation to the present study with respect to the respondents, instrument used, the social norm construct, the analytical technique used, online learning related issues, and the theory of planned behavior itself.

\section{Respondents}

Not only the respondents and the setting in which the study took place should be considered but the online course characteristics as well. The convenience sample of learners (respondents), though addressed by statistical procedures, were students in a business school taking an introductory course in management information systems. This is problematic on many levels, including bias, size, and demographic controls. Therefore generalizing the findings in terms of behavior and intentions to other schools may be limited. The general idea behind this limitation lies within the changes in perception of the phenomenon of interest (Agarwal \& Karahanna, 2000). As a result, there is a great need to identify the boundary conditions of the theoretical model as it relates to demographic variables such as age, gender, ethnicities, computer competencies, and cognitive style. Other possible limitations are the interface design and type (the use of icons and menus for example) and the course itself. Some courses lend themselves to be appropriate for online while other do not. The identification of courses appropriate for online systems needs to be studied.

\section{Instrument Used}

Evidence of improved learning has been associated with improved learning outcomes but the selfreport measures used in this study are not themselves direct indicators of improved learning out- 
comes. Further, though we have continued to validate the instrument, it cannot be assumed that the questions themselves adequately addressed the constructs for which they were designed.

\section{Social Norm Construct}

Student perception of social presence was found to influence slightly performance on the examination and strongly written assignments (Pacciano, 2002). Social presence in this class depended upon participation in the weekly discussions, which encouraged an appreciation for the points of view of others. Those who felt the "presence" of their colleagues as a result of what was read and written on the discussion board perhaps could relate better to an activity such as the written assignment. Their sense of "presence" did not relate to an objective, multiple-choice examination because it was not an expressive activity but an asocial impersonal activity.

\section{Online Related Issues}

Students had a relatively less favorable response when comparing their ability to learn the material in the online computer course to their ability to learn the material in the traditional classroom setting. Responses related to students' motivation to complete the assignments in the online computer course also are not as positive. In the online computer course, these two learning outcomes involve active learning as compared to a more common use of passive learning in the traditional classroom. Since active learning involves more time, energy, and self-reliance, the response could be the result of the difficulty adapting to this kind of learning involved rather than the medium used.

\section{The Theory of Planned Behavior}

At the same time, many issues remain unresolved. The theory of planned behavior traces attitudes, subjective norms, and perceived behavioral control to an underlying foundation of beliefs about the behavior. Although there is plenty of evidence for significant relations between behavioral beliefs and attitudes toward the behavior, between normative beliefs and subjective norms, and between control beliefs and perceptions of behavioral control, the exact form of these relations is still uncertain. The most widely accepted view, which describes the nature of the relations in terms of expectancy-value models, has received some support, but there is clearly much room for improvement. Of particular concern are correlations of only moderate magnitude that are frequently observed in attempts to relate belief-based measures of the theory's constructs to other, more global measures of these constructs. Optimally rescaling measures of belief strength, outcome evaluation, motivation to comply, and the perceived power of control factors can help overcome scaling limitations, but the observed gain in correlations between global and belief-based measures is insufficient to deal with the problem.

\section{Practical Implications and Future Research}

\section{Practical Implications}

This research was motivated by a need to design and implement an OES based on the human and social aspects of knowledge management. The design of the OES is guided towards providing an effective and holistic learning experience to students. In effect, the design entails cognitive exercises and collaborative interaction. The design was then assessed by administering a questionnaire to the students to measure their perceptions and behavior towards the OES.

There are several potentially important implications. The findings demonstrate the superiority of the TPB in explaining students' behavior of the OES in higher education. Moreover, structural modeling demonstrates the importance of $\mathrm{PBC}$ as the variable to provide the strongest influence 
on intentions. What was learned from this study include the value of PBC for the assessment of the OES. Creating holistic-based OESs could enhance attitudes and perceived learning. Perceived learning has been shown to influence overall learning experience.

Educational institutions are highly interested in developing online courses. However, they do not now have a theory based design nor the expertise in its development. The design and implementation, as well as the theoretical foundation and methodology, presented here may provide an initial template for implementing online courses after which they can be refined to meet the educational and organizational needs. The outcome would be a faster development cycle per course and reduced design and planning costs. From the instructor's viewpoint, the role of the constructs' relationships is of importance for the assessment of different OES designs which can be useful for the integration of content into complete online courses as well as curricula. Certainly, colleges and universities could use the results to enhance their understanding of what makes students have a richer learning experience using the OES for better performance.

\section{Suggestions for Future Research}

The proposed design of the OES is just one solution focused on the human and social aspects of knowledge (or course content and instructor expertise) management. Variation could be many based on the context at which the OES is going to be implemented. The present work provides a fertile ground for future research:

1. From a design perspective:

a. The interface design and type (the use of icons and menus for example) can play an important role in perceived ease of use and hence may influence perceived usefulness and attitudes. The design and assessment of different interfaces and their influence on learning would be of great value to human computer interaction research.

b. Cognitive mapping of the design variable to allow designers identify when and where to enhance the OES based on pre-determined objectives.

2. From the assessment perspective:

a. There is a great need to identify the boundary conditions of the theoretical model as it relates to demographic variables such as age, gender, ethnicities, computer competencies, and cognitive style.

b. Some courses lend themselves to be appropriate for online while other do not. Exploring variables that lead to the identification of appropriate online courses would be of value to designers.

c. Using an OES, learning outcomes involve active learning as compared to a more common use of passive learning in the traditional classroom. Since active learning involves more time, energy, and self-reliance, the response could be the result of the difficulty adapting to this kind of learning involved rather than the medium used. Optimally rescaling measures of belief strength, outcome evaluation, motivation to comply, and the perceived power of control factors can help overcome scaling limitations, but the observed gain in correlations between global and belief-based measures is insufficient to deal with the problem.

\section{Guidelines for OES Designers}

The process of designing, implementing, and running an online course should be thought of as a conversion of the lecture-based course rather than a creation of a new one. This viewpoint is based on the assumption that the instructor has already taught the course in the classroom. Con- 
version should be viewed as a mapping of what the instructor does in each lecture (in terms of learning activities and objectives) and throughout the session. In doing so, the instructor then attempts to reproduce/simulate the learning process online. The implications are towards the transformation of students' and instructors' behavior once the course is online. The conversion of a course online entails three major components. These components are based on our experiences in designing, implementing, maintaining, and evaluating an online course for a period of 4 sessions. The course is management information systems at the undergraduate level where 150 to 200 stu-

dents registered for it each session. The components can be considered as basic guidelines, which can be refined, based on the environment and context at which the online course is being developed.

\section{- Design components}

a. Separate the administrative section of the course from the learning activities of the course.

- Three administrative elements were included in the presented OES: Calendar based agenda, white pages, and a 1-way instructor-to-student bulletin board.

- It is worth elaborating on the bulletin board because it has been shown to be very effective. The bulletin board here was used to keep the students login into the system on a regular basis because I would post messages on a regular basis. These messages could be a description of an important concept, or a motivational message to study before the midterm. Most importantly, if three or more students asked me the same question, then I would post the question and answer. This way the bulletin board can be used as a dynamic FAQ.

b. Suggest a few steps where students can follow to learn each topic or chapter. This guidance has been appreciated. Those steps do not need to include heavy multimedia, video, animation, or sound, but they could be as simple as "look-Listen-Learn." In the presented OES, three steps were suggested:

- Step 1: Read, view video, view presentations

- Step 2: Practice online quizzes

- Step 3: Discuss instructor-specified topics with colleagues

c. Include a forum where students can communicate with each other about anything. I called it eTalk. This actually brings students together where they can help each other with course related questions.

\section{- Implementation process}

Once your course has been converted, then it has to be put in electronic format and on the web. This includes technological issues and is beyond the scope of this paper. Once you are in the implementation process, we assume that your course is ready to be utilized via a web browser.

a. You need to create an orientation for the course. I found that students who missed the orientation session had many questions later during the session, while only few from those that were present had any questions. The orientation session can be viewed as the element that makes the virtual environment tangible by providing students with the walls to their online classroom. The orientation session should be completed by distributing a document that includes the topics discussed below: 
- Welcome students, introduce yourself, and follow with a motivational introduction of the online course.

- Describe the nature of online courses. Not everybody has the traits to follow an online course. What should students be aware of concerning their personality traits and behavior so they can minimize negative affect about the online course and maximize the chance to perform well?

- Describe the nature of the course. Is the course difficult or not and why? Experiences with the course with students taking online and face-to-face.

- Course overview and objectives.

- What should the students' expectation from the course be?

- What are the instructors' expectations from the students?

- Describe the online environment and present the web pages.

- Provide details to the marking scheme. How will students be evaluated?

- Identify key dates such as midterms, tests, assignments, and projects.

- Questions?

b. Course content:

- Include a copy or your notes and presentation in the white pages.

- Try to present the online topics/chapter in chunks of six or seven. This helps very much the retention and assimilation of information required to be learned.

- Avoid including large files or multimedia that require add-ons. Depending on the level of the course and the student group, technology can be either a blessing or a nightmare. In my experiences technology was a headache and in effect I had to create a substantial amount of documentation and instructions on how-to-do modules. Examples are on how to download, install, and use quicktime and winzip.

c. Instructor-student relationship

- The bulletin board discussed above was found to be highly effective.

- Email response time was also found to be a critical element in perceptions of control and attitudes towards the course. When the response time was long (in terms of days) students perceived that they were less in control with following the course and their attitudes shifted from positive to negative by viewing the course to be more difficult to follow. Today, my response time is $95 \%$ within an hour and students highly appreciate it. They actually express this appreciation by email.

- Students do not read (I am being general and specific to my case) or at least avoid it at all cost. Instructors need to encourage appropriate online expectations. When a student asks a question where the answer is available either in the bulletin board or in the white pages, the instructor should direct the student to where that answer is and not answer the question. If the instructor does answer the question, the student(s) become lazy and dependent on the instructor. Prior to me giving the course, another instructor 
gave the course under a completely different design. The instructor reported emails in excess of 75 per week. After three sessions, I have less than five emails per week increasing to fifteen for the week prior to a submission of a project, midterm, or final. These are the implications of transforming roles for both students and instructors.

- The instructor can also make office hours where the response to the email is instantaneous. Any emails outside the office hours will be answered during office hours. I usually use this approach during the summer sessions and it works very well. Expectations are clear.

d. Course management

For an effective online course

- Assume nothing.

- Address students concerns and feedback in the design of the course.

- Solicit students for way to enhance the course. They usually give good suggestions. I have enhanced the course three times based on students' suggestions.

- Try to provide documentation that is written as if you are talking to the students. This provides a feeling of conversation and reduces loneliness.

- Provide motivational messages a few times along the session. In other words, stay in touch.

- Insist on students coming to the orientation. Not all will be able to come. I have videotaped my orientation session and provide it to the students on a CD ROM. This way they can have it if they miss the session and they can review it.

\section{- Human-Computer Interaction}

The course web pages should be also designed properly. This introduces another element into the student's perspective. The following are some guidelines to that effect:

a. Keep all pages simple. Too many images, pictures, and moving animated objects simply distract students from the actual activity.

b. Provide a student manual on how to ensure that their system is setup for proper operation with the course web pages (navigational instruction manual).

c. Provide a procedure to test that the computer functions properly with all the course components.

d. Provide alternate computers on campus as back up.

e. Provide support in case of technical problems.

f. Provide instructional cues that help students navigate the pages.

g. Maintain a certain level of consistency in colors, objects, and words on the pages.

\section{Conclusions}

This research was driven by the need to bring together design processes, learning principles, and MIS methodology. This structured design-assessment approach is multidisciplinary and not traditionally followed by researchers in the fields of education, engineering, and MIS. Acknowledging 
the fact that the nature of information technologies has changed considerably, we argue that in the case of online learning, we need to focus our attention to a complete and structured learningdesign-assessment approach to development. To this end, we describe a case, which follows this approach by:

1. Understanding the nature of the course

2. Evaluating and adopting learning principles that would enhance the learning experiences of students

3. Designing the technologies supporting the adopted learning principles

4. Following a structured MIS approach to understand the different dimension to the student's learning experiences by

- Selecting one or more models to test (For example Theory of Reasoned Action, Technology Acceptance Model, and Theory of Planning Behavior)

- Designing the experiment (issues such as completing the questionnaire prior, post and during the course)

- Analyzing data using a structural modeling approach.

Not only does this approach provide a structured framework to design and assess online learning, it also:

- $\quad$ Provides controls at different levels to reproduce under experimental setups

- Allows researchers to implement under different contexts hence facilitating the analysis of the mediating effects of the different contexts on student experiences

- $\quad$ Permits the studying of direct and indirect effects of constructs on one another

- $\quad$ Can give tangible and measurable results that may tell the researcher how to modify the design to obtain enhanced student experiences

From a practical perspective, our findings provide the following implications:

1. The results point to the capability of the Theory of Planned Behavior in explaining intentions to take online courses

2. The elements of design of the knowledge management system for professionals

3. The explosion of ecommerce in the educational perspective has stressed the need to better design

In conclusion, the primary goal of this paper was to enhance our understanding of the underlying design elements for the knowledge management of an online educational system in an educational environment and assessing the student's experiences with the system. We presented a learning-design-assessment approach that was shown to be effective in the educational learning context. We also demonstrated the importance of the theory of planned behavior and its superiority in explaining variances compared to the technology acceptance model. This study offers new evidence that a properly designed learning environment can result in favorable behavior of students toward their online learning experience. 


\section{References}

Adams, D. A., Nelson, P. P., \& Todd, P. A. (1992). Perceived usefulness, ease of use, and usage of information technology: A replication. MIS Quarterly, 16(2), 227-247.

Agarwal, R., \& Karahanna, E. (2000). Time flies when you're having fun: Cognitive absorption and beliefs about information technology usage. MIS Quarterly, 24(4), 665-694.

Ajzen, I. (1985). From intentions to actions: A theory of planned behavior. In J. Kuhl \& J. Beckmann (Eds.), Action control: From cognition to behavior (pp. 11-39). New York: Heidelberg: Springer.

Ajzen, I. (1988). Attitudes, personality and behavior. Dorsey Press.

Ajzen, I., \& Fishbein, M. (1980). Understanding attitudes and predicting social behavior. Englewood Cliffs, NH: Prentice Hall.

Ajzen, I., \& Madden, T. J. (1986). Prediction of goal directed behavior: Attitudes, intentions and perceived behavioral control. Journal of Experimental Social Psychology, (22), 453-474.

Avdic, A., \& Westin, O. (2002). A local information systems perspective on knowledge management. The Xth European conference on Information Systems, June.

Azarmsa, R. (1991). Educational computing: Principles and applications. Englewood Cliffs, NJ: Educational Technology.

Benham, H., \& Reymond, B. (1996). IT adoption: Evidence from a voice mail introduction. ACM CP, 3-26.

Bozionelos, G., \& Bennett, P. (1999). The theory of planned behavior as predictor of exercise. Journal of Health Psychology, 4(4), 517-529.

Brandt, S. D. (1996). Teaching the net: Innovative techniques in internet training. 11th Annual Computers and Business Conference, Washington, DC., February.

Brown, I. J. T. (2002). Individual and technological factors affecting perceived ease of use of web-based learning technologies in a developing country. EJISDC, 9(2), 1-15.

Carlson, P. A. (1998). Advanced educational technologies - Promise and puzzlement. Journal of Universal Computer Science (JUCS), 4(3), 210-215.

Chau, K. Y. P. (1996). An empirical assessment of a modified technology acceptance model. Journal of management information systems, 13(2), 185-204.

Chau, K. Y. P. \& Hu, J. P. (2002). Examining a model of information technology acceptance by individual professionals: An exploratory study. Journal of Management Information Systems, 18(4), 191-229.

Chin, K. L. (1999). A study into students' perceptions of web-based learning environment. HERDSA Annual International Conference, Melbourne, July.

Conlon, T. (1997). The internet is not a panacea. Scottish Educational Review, 29(1), 30-38.

Cronin, P. (1997). Learning and assessment of instruction. Unpublished report, Edinburgh: University of Edinburgh Centre for Cognitive Science. Retrieved from http://www.cogsci.ed.ac.uk/ paulus/work/vranded/litconsa.txt

Dalgarno, B. (2001). Technologies supporting highly interactive learning resources on the web: An analysis. Journal of Interactive Learning Research, 12(2/3), 153-171.

Davenport, T. H. (1995). Business process reengineering: Where it's been, where it's going. In V. Grover and W. Kettinger (Eds.), Business process change: Reengineering concepts, methods and technologies (pp. 1-13). Hershey, PA: Idea Group.

Davenport, T. H., \& Prusak, L. (1998). Working knowledge: How organizations manage what they know. Boston, MA: Harvard Business School Press. 
Davis, D. F. (1986). A technology acceptance model for empirically testing new end-user information systems: Theory and results. Doctoral Dissertation, Sloan school of management, Massachusetts Institute of Technology.

Davis, D. F. (1989). Perceived usefulness, perceived ease of use, and user acceptance of information technology. MIS Quarterly, 13(3), 319-339.

Davis, D. F., Bagozzi, P. R., \& Warshaw, R. P. (1989). User acceptance of computer technology: A comparison of two theoretical models. Management Science, 35(8), 982-1003.

Dole, J. A., \& Sinatra, G. M. (1998). Reconceptualizing change in the cognitive construction of knowledge. Educational Psychologist, 33(2/3), 109-128.

Drucker, P. F. (1995). Managing in a Time of Great Change. New York, NY: Truman Talley.

Drucker, P. F. (1994). The age of social transformation. The Atlantic Monthly, November.

Enockson, J. (1997). An assessment of an emerging technological delivery for distance education. Unpublished doctoral dissertation, Northern Arizona University.

Ewing, J. M., Dowling, J. D., \& Coutts, N. (1998). Learning using the World Wide Web: A collaborative learning event. Journal of Educational Multimedia and Hypermedia, 8(1), 3-22.

Fishbein, M., \& Ajzen, I. (1975). Belief, attitude, intention, and behavior. Reading, MA: Addison-Wesley.

Fornell, C. \& Larcker, F. D. (1981). Structural equation models with unobservable variables and measurement error: Algebra and statistics. Journal of Marketing Research, XVIII, 362-368.

Gattiker, E. U. (1984). Managing computer-based office information technology: A process model for management. In. H. Hendrick \& O. Brown (Eds.), Human factors in organizational design. Amsterdam, The Netherlands: North-Holland.

Green, K. C. (1998). Colleges struggle with IT planning:The 1998 national survey of information technol-

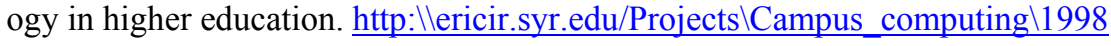

Guilford, J. (1963). Intellectual resources and their values as seen by scientists. In C. Taylor \& F. Barron, (Eds.), Scientific creativity: Its recognition and development. New York: John Wiley and Sons.

Gupta, S., \& Bostrom, P. R. (2009). Technology-mediated learning: A comprehensive theoretical model. Journal of the Association for Information Systems, 10(9), 686-714.

Hedberg, J., Harper, B., \& Corrent-Agostinho, S. (1998). Creating a postgraduate virtual community: Issues for authors and students as authors. Apple University Consortium Academic Conference, University of Melbourne, Melbourne.

Helmi, D., Haynes, G., \& Maun, C. (2000). Internet teaching methods across the disciplines. Journal of Applied Business Research, 16(4), 1-13.

Hodgson, V. (1997). New technologies and learning: Accepting the challenge. In J. Burgoyne \& M. Reynolds (Eds.), Management learning. London: SAGE Publications.

Hood, P. (2002). Perspectives on knowledge utilization in education. WestEd. Retrieved from http://www.wested.org/online pubs/perspectives.pdf

Hunt, N. P. (1998). Designing instruction for the web: Incorporating new conceptions of the learning process. Ed-Media-Telecom 98 World Conference on Educational Multimedia and Hypermedia and World Conference on Educational Telecommunications, June.

Johnson, D. S., Aragon, S. R., Shaik, N., \& Palma-Rivas, N. (2000). Comparative analysis of learners satisfaction and learning outcomes in online and face-to-face learning environments. Journal of Interactive Learning Research, 11(1), 29-49.

Jonassen, D., Davidson, M., Collins, M., Campbell, J., \& Haag, B. (1995). Constructivism and computermediated communication in distance education. The American Journal of Distance Education, 9(2), 7 26. 
Kallol, K. B., Hart, P., \& Cerveny, R. (2002). An empirical testing of the theory of planned behavior in explaining IT adoption. Decision Science Institute 2002 Annual Meeting Proceedings.

Karahanna, E., Straub, D. W., \& Chervany, N. L. (1999). Information technology adoption across time: A cross-sectional comparison of pre-adoption and post-adoption beliefs. MIS Quarterly 23(2), 183-213.

Keller, J. M., \& Suzuki, K. (1988). Use of the ARCS motivation model in courseware design. In D. H. Jonassen (Ed.), Instructional designs for microcomputer courseware (pp. 401-434). Hillsdale, NJ: Lawrence Erlbaum Associates.

Kolb, D. (1984). Experiential learning: Experience as the source of learning and development. Englewood Cliffs, NJ: Prentice-Hall.

Kuehn, S. A. (1994). Computer-mediated communication and instructional settings: A research agenda. Communication Education, 43, 171-183.

LaRose, R., Gregg, J., \& Eastin, M. (1998). Audiographic telecourses for the web: An experiment. Journal of Computer-Mediated Communications, 4(2). Retrieved from http://www.ascusc.org/jcmc/vol4/issue2/larose.html

Lee, D., Park, J., \& Ahn, J. (2001). On the explanation of factors affecting e-commerce adoption. Proceedings of the 22nd International Conference on Information Systems (ICIS 2001), New Orleans, Louisiana, USA, December, 109-120.

Legris, P., Ingham, J., \& Collerette, P. (2003). Why do people use information technology? A critical review of the technology acceptance model. Information and Management, 40, 191-204.

Lindner, R. (2001). Expertise and Role Identification for Learning Environments (ERILE). Proposed Standard draft for German DIN NI-36 (planned to be a mirror for the ISO/IEC JTC1 SC36). http://www.igd.fhg.de/ lindner/PROMETEUS/SIG-DESIGN Meeting-Point.html.

Mayer, R. E. (1989). Models for understanding. Review of Educational Research, 59(1), 43-64.

McCartney, L. (1998). Getting smart about knowledge management. Industry Week, 247(9), 30-37.

McCormack, C., \& Jones, J. D. (1997). Building a web-based education system. Wiley Computer Publishing.

Miller, M. S., \& Miller, L. K. (1999). Using instructional theory to facilitate communication in web-based courses. Educational Technology \& Society, 2(3). Retrieved from http://ifets.ieee.org/periodical/vol_3_99/miller.html

Mathieson, K. (1991). Predicting user intentions: Comparing the Technology Acceptance Model with the Theory of Planned Behavior. Information Systems Research, 2, 173-191.

Moore, M. G., \& Kearsley, G. (1996). Distance education: A systems view. Wadsworth Publishing.

Nissen, M., Kamel, M., \& Sengupta, K. (2000). Integrated analysis and design of knowledge systems and processes. Information Resources Management Journal, 13(1), 24-43.

Nurminen, M. (1995). Knowledge work and knowledge act. In B. Dahlbom (Ed.), The infological equation - Essays in honor of Borje Langefors. Report 6, Gothenburg Studies in Information Systems. Department of Computer Sciences, Chalmers University of Technology and the University of Goteborg.

Oliver, R., Herrington, J., \& Omari, A. (1996). Creating effective instructional materials for the World Wide Web. Australian World Wide Web Conference, 485-491.

Olson, G., \& Olson, J. (2000). Distance matters. Human-Computer Interaction, 15(2, 3), 107-137.

Pacciano, A. G. (2002). Beyond student perceptions: Issues of interaction, presence, and performance in an online course. Journal of Asynchronous Learning Networks, 6(1).

Piaget, J. (1952). The origin of intelligence in children. New York: Basic Books.

Piaget, J., \& Inhelder, B. (1969). The psychology of the child. New York: Basic Books. 
Retalis, S., \& Avgeriou, P. (2002). Modelling Web-Based Instructional Systems. Journal of Information Technology Education, 1(1), 25-42. Retrieved from http://www.jite.org/documents/Vol1/v1n1p025042.pdf

Rivard, H. S. (1988). Factors for success for end-user computing. Communications of the ACM, 31(5), $552-$ 561.

Roberts, B. (1996). Internet as knowledge manager. Web Week, 9 September, p. 30.

Ruzic, R. (2000). New solutions, new barriers: Current uses of the web in higher education. Annual Meeting of the American Educational Research Association, New Orleans, LA.

Saadé, G. R. (2007). Dimensions to perceived usefulness: Towards an enhanced assessment. Decision Sciences Institute - Decision Sciences Journal of Innovative Education, 5(2), 289-310.

Saadé, G. R. \& Bahli, B. (2005). The impact of cognitive absorption on perceived usefulness and perceived ease of use in on-line learning: An extension of the Technology Acceptance Model. Information \& Management, 42, 317-327.

Saadé, G. R. \& Galloway, I. (2005). Understanding the Acceptance of Multimedia Applications for Learning. Issues in Informing Science and Information Technology, 2, 287-296.

Saadé, G. R., \& Huang, Q. (2009). Meaningful learning in discussion forums: Towards discourse analysis. Issues in Informing Science and Information Technology, 6, 87 - 99. Retrieved from http://iisit.org/Vol6/IISITv6p087-099Saade675.pdf

Saadé, G. R., \& Kira, D. (2006). The emotional state of technology acceptance. Issues in Informing Science and Information Technology, 3, 529-539. Retrieved from http://informingscience.org/proceedings/InSITE2006/IISITSaad145.pdf

Saadé, G. R. \& Kira, D. (2007). Mediating the impact of technology usage on perceived ease of use by anxiety. Computers \& Education, 49(4), 1189-1204.

Saadé, G. R., \& Kira, D. (2008). Is usage predictable using belief-attitude-intention paradigm? Issues in Informing Science and Information Technology, 5, 591-599. Retrieved from http://proceedings.informingscience.org/InSITE2008/IISITv5p591-599Saade503.pdf

Saadé, G. R., \& Kira, D. (2009). The e-motional factor of e-learning. Journal of Asynchronous Learning Networks, 13(4), 57-72.

Saadé, G. R., Nebebe, F., \& Tan, W. (2007). Viability of the "Technology Acceptance Model" in multimedia learning environments: A comparative study. Interdisciplinary Journal of Knowledge and Learning Objects, 3, 175-184. Retrieved from http://www.ijello.org/Volume3/IJKLOv3p175-184Saade393.pdf

Schutte, G. J. (1997). Virtual teaching in higher education: The new intellectual superhighway or just another traffic jam? Retrieved from http://www.csun.edu/sociology/virexp.htm

Sunal, W. D., Sunal, S. C., Odell, R. M., \& Sundberg, A. C. (2003). Research-supported best practices for developing online learning. The Journal of Interactive Online Learning, 2(1), 1-40.

Thomas, C. J., Kellogg, A. W., \& Erickson, T. (2001). The knowledge management puzzle: Human and social factors in knowledge management. IBM Systems Journal, 40(4), 863-884.

Valenta, A., Therriault, D., Dieter, M., \& Mrtek, R. (2001). Identifying student attitudes and learning styles in distance education. Journal of Asynchronous Learning Networks, 5(2), 111-127.

Vygotsky, L. S. (1962). Thought and language. Cambridge, MA: MIT Press.

Wan, Z., Wang, Y. \& Haggerty, N. (2008). Why people benefit from e-learning differently: The effects of psychological processes on e-learning outcomes. Information \& Management, 45, 513-521.

Webster, J., \& Hackly, P. (1997). Teaching effectiveness in technology-mediated distance Learning. Academy of management journal, 40(6), 1282-1309. 
Werts, C. E., Joreskog, K. G., \& Linn, R. L. (1973), Identification and estimation in path analysis with unmeasured variables. American Journal of Sociology, 78, 1469-1484.

\section{Biographies}

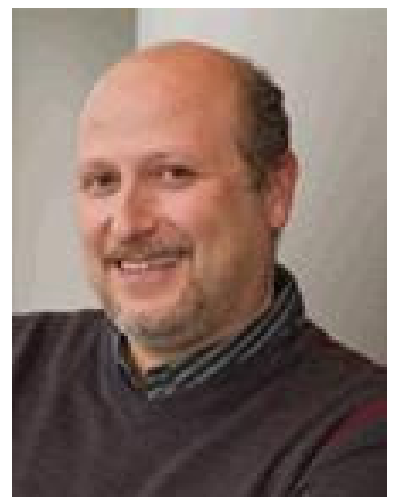

Dr. Raafat George Saade has been teaching in the faculty since 1998. He obtained his Ph.D. in 1995 (Concordia University) after which he received the Canadian National Research Council postdoctoral fellowship, which he completed at McGill University in Montreal. Dr. Saade has published in journals such as Information \& Management, Decision Sciences, and Ex-pert Systems with Applications. His research interests include the development and assessment of information systems, the supply chain of digital information products, and sustainability of information technology.

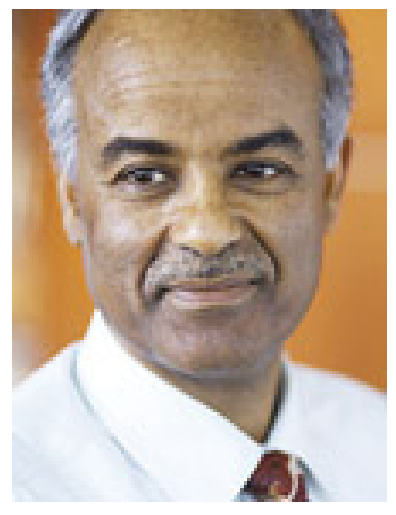

With the Faculty since 1986, Dr. Nebebe obtained his BSc from Haile Se-lassie I University in Addis Ababa, Ethiopia, his MSc from Southampton University in Southampton, England and his $\mathrm{PhD}$ from Queen's University in Kingston, Canada. He teaches undergraduate and graduate courses applied linear statistical models, research methods, managerial statistics and business statistics. His research is Bayesian and empirical Bayes methods in small areas, Gibbs sampling, data modeling and statistical computing.

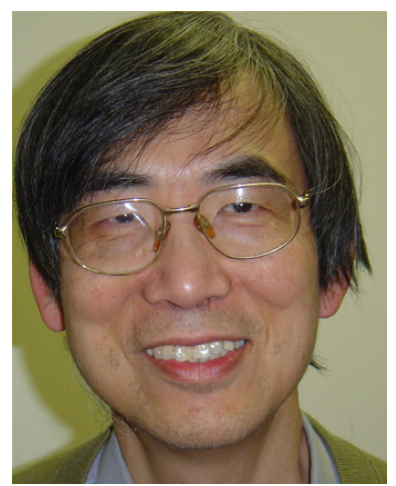

With the Faculty since 1991, Tak Mak obtained his BSc degree in Mathe-matics from the Chinese University of Hong Kong. He also holds an MA in Mathematics from York University and a PhD in Statistics from the Univer-sity of Western Ontario. Prior to joining Concordia University, he taught at the Hong Kong Polytechnic, the University of Hong Kong and the Memorial University of Newfoundland. He teaches statistical models for business research, survey design and analysis, measurement error models and multivariate analysis. His research focuses on statistical methods using the Bootstrap, heteroscedastic regression models, analysis of survey data, statistical quality control. Results published in different areas, including errors-invariables, interclass and intraclass correlations, ranked data, analyses of misclassified data, regression models, statistical computing, time series analysis, survey sampling, and statistical quality control. He had served as an Associate Editor of the Canadian Journal of Statistics and was an elected member of ISI. He was appointed by NSERC as a committee member of the Statistics Grant Selection Committee for the period September 1994 to May 1997. 